\title{
Tumor-induced STAT3 activation in monocytic myeloid-derived suppressor cells enhances stemness and mesenchymal properties in human pancreatic cancer
}

\author{
Roheena Z. Panni · Dominic E. Sanford • Brian A. Belt $\cdot$ Jonathan B. Mitchem $\cdot$ Lori A. Worley $\cdot$ Brian D. Goetz \\ Pinku Mukherjee · Andrea Wang-Gillam • Daniel C. Link • David G. DeNardo $\cdot$ S. Peter Goedegebuure • \\ David C. Linehan
}

Received: 12 October 2013 / Accepted: 22 February 2014 / Published online: 21 March 2014

(C) The Author(s) 2014. This article is published with open access at Springerlink.com

\begin{abstract}
Pancreatic cancer (PC) mobilizes myeloid cells from the bone marrow to the tumor where they promote tumor growth and proliferation. Cancer stem cells (CSCs) are a population of tumor cells that are responsible for tumor initiation. Aldehyde dehydrogenase-1 activity in PC identifies CSCs, and its activity has been correlated with poor overall prognosis in human PC. Myeloid cells have been shown to impact tumor stemness, but the impact of immunosuppressive tumor-infiltrating granulocytic and monocytic myeloidderived suppressor cells (Mo-MDSC) on ALDH $1^{\text {Bright }}$ CSCs and epithelial to mesenchymal transition is not well
\end{abstract}

Electronic supplementary material The online version of this article (doi:10.1007/s00262-014-1527-x) contains supplementary material, which is available to authorized users.

R. Z. Panni · D. E. Sanford · B. A. Belt · J. B. Mitchem ·

L. A. Worley · B. D. Goetz · S. P. Goedegebuure ·

D. C. Linehan $(\square)$

Department of Surgery, Washington University School of Medicine, 660 South Euclid Ave., Box 8109, St. Louis, MO 63110, USA

e-mail: linehand@wudosis.wustl.edu

R. Z. Panni

e-mail: pannir@wudosis.wustl.edu

P. Mukherjee

Department of Biology, University of North Carolina

at Charlotte, Charlotte, NC, USA

A. Wang-Gillam · D. C. Link · D. G. DeNardo

Division of Oncology, Department of Medicine, Washington

University School of Medicine, St. Louis, MO, USA

A. Wang-Gillam · D. C. Link · D. G. DeNardo ·

S. P. Goedegebuure · D. C. Linehan

Alvin J. Siteman Cancer Center, St. Louis, MO, USA understood. In this study, we demonstrate that Mo-MDSC $\left(\mathrm{CD} 11 \mathrm{~b}^{+} / \mathrm{Gr}^{+} / \mathrm{Ly} 6 \mathrm{G}^{-} / \mathrm{Ly} 6 \mathrm{C}^{\mathrm{hi}}\right)$ significantly increase the frequency of ALDH $1^{\text {Bright }}$ CSCs in a mouse model of PC. Additionally, there was significant upregulation of genes associated with epithelial to mesenchymal transition. We also found that human $\mathrm{PC}$ converts $\mathrm{CD} 14^{+}$peripheral blood monocytes into Mo-MDSC (CD14 $/ 4^{+} \mathrm{HLA}_{-} \mathrm{DR}^{\text {low/-}}$ ) in vitro, and this transformation is dependent on the activation of the STAT3 pathway. In turn, these Mo-MDSC increase the frequency of ALDH $1{ }^{\text {Bright }} \mathrm{CSCs}$ and promote mesenchymal features of tumor cells. Finally, blockade of STAT3 activation reversed the increase in ALDH1 ${ }^{\text {Bright }}$ CSCs. These data suggest that the PC tumor microenvironment transforms monocytes to Mo-MDSC by STAT3 activation, and these cells increase the frequency of ALD$\mathrm{H} 1{ }^{\text {Bright }}$ CSCs. Therefore, targeting STAT3 activation may be an effective therapeutic strategy in targeting CSCs in PC.

Keywords Monocytic MDSC - Stem cell - Epithelial to mesenchymal transition - Pancreatic cancer - STAT3 activity

\begin{tabular}{|c|c|}
\hline \multicolumn{2}{|c|}{ Abbreviations } \\
\hline CCR2 & Chemokine ( $\mathrm{C}-\mathrm{C}$ motif) receptor 2 \\
\hline CSC & Cancer stem cell \\
\hline G-CSF & $\begin{array}{l}\text { Granulocyte colony-stimulating factor } \\
\text { (CSF-3) }\end{array}$ \\
\hline G-MDSC & $\begin{array}{l}\text { Granulocytic myeloid-derived suppressor } \\
\text { cell }\end{array}$ \\
\hline Mo-MDSC & Monocytic myeloid-derived suppressor cell \\
\hline $\mathrm{PC}$ & Pancreatic cancer \\
\hline STAT3 & $\begin{array}{l}\text { Signal transducer and activator of transcrip- } \\
\text { tion } 3\end{array}$ \\
\hline $\mathrm{AM}$ & Tumor-associated macrophage \\
\hline
\end{tabular}




\section{Introduction}

Pancreatic cancer (PC) is a highly aggressive malignancy which is characterized by early metastasis and chemotherapeutic resistance [1]. PC has a uniquely dense stroma with abundant leukocytes, which are predominantly myeloid cells. These myeloid cells are heterogeneous; primarily comprised of macrophages and monocytic and granulocytic myeloid-derived suppressor cells (Mo- and G-MDSC, respectively) [2]. These cells are produced in the bone marrow, are actively recruited to the tumor microenvironment by tumor-derived chemokines, and promote tumor growth and spread through various mechanisms [3-5].

Their clinical importance is demonstrated by the finding that in a number of cancer types including PC, increased prevalence of myeloid cells in the tumor microenvironment is an independent prognostic factor for survival [6]. Tumor-associated myeloid cells have been shown to correlate with disease stage, resectability, and survival in PC [7, 8]. Typical of tumor-infiltrating myeloid cells is their ability to suppress antitumor immunity [9]. In addition, they can also directly promote tumor cell proliferation, invasion and thus facilitate metastasis, and therapeutic resistance $[7,10]$.

Cancer stem cells (CSCs) are an important subpopulation of tumor cells which are capable of tumor initiation and are resistant to chemotherapy [11]. In PC, CSCs were first identified as $\mathrm{CD} 24^{+} / \mathrm{CD} 44^{+} / \mathrm{ESA}^{+}$cells [12]. Aldehyde dehydrogenase-1 (ALDH1) is a relatively new marker which is an intracellular detoxifying enzyme originally identified as a phenotypic marker for hematopoietic stem cells $[13,14]$. We and others have previously demonstrated that ALDH1 is also an important marker of CSCs in PC $[15,16]$. In fact, patients having tumors with increased ALDH $1{ }^{\text {Bright }}$ CSCs have decreased progression free and overall survival [16]. It is not entirely clear how levels of ALDH $1{ }^{\text {Bright }}$ CSCs are regulated, but there is mounting evidence for a dynamic interplay between the stroma and tumor cells which promotes epithelial to mesenchymal transition (EMT) and tumor stemness [17, 18].

The role of mature tumor-associated macrophages (TAMs) in promoting stemness in a murine model of PC has been demonstrated by Mitchem et al. However, the role of Mo-MDSC in PC is not well understood. In this study, G-MDSC and Mo-MDSC from both mice (G-MDSC: $\mathrm{CD} 11 \mathrm{~b}^{+} / \mathrm{Gr}^{+} / \mathrm{Ly} 6 \mathrm{G}^{+} / \mathrm{Ly} 6 \mathrm{C}^{\mathrm{mid}}$, Mo-MDSC: $\mathrm{CD} 1 \mathrm{~b}^{+} / \mathrm{Gr}^{+} / \mathrm{Ly} 6 \mathrm{G}^{-} / \mathrm{Ly} 6 \mathrm{C}^{\mathrm{hi}}$ ) and humans (G-MDSC: $\mathrm{Lin}^{-} / \mathrm{CD} 11 \mathrm{~b}^{+} / \mathrm{CD} 33^{+} / \mathrm{CD} 15^{+}$, Mo-MDSC: $\mathrm{Lin}^{-} / \mathrm{CD} 11 \mathrm{~b}^{+} /$ $\left.\mathrm{CD} 3^{+} / \mathrm{CD} 14^{+} / \mathrm{HLA}^{-D R^{\text {low/-}}}{ }^{-}\right)[19,20]$ were assessed for their impact on ALDH1 ${ }^{\text {Bright }}$ CSC in mouse and human PC. We demonstrate that Mo-MDSC-infiltrating PC tumors promote the ALDH1 ${ }^{\text {Bright }} \mathrm{CSC}$ population by activation of STAT3. We also show that cancer stem cell promoting activity can be blocked by inhibition of the STAT3 signaling pathway.

\section{Materials and methods}

Bone marrow samples from pancreatic cancer patients and healthy controls and collection of PC tissue from patients

Blood, bone marrow samples $(N=16)$, and tumor samples $(N=11)$ were collected from patients with resectable PC at Barnes-Jewish Hospital (St. Louis, MO, USA). These patients received no chemotherapy or radiation therapy prior to surgery. Informed consent was obtained on all patients in accordance with Institutional Review Board (IRB)-approved protocol. Normal bone marrow was obtained from agematched healthy cancer free volunteers $(N=7)$. Bone marrow samples were collected in vacuum tubes containing lithium heparin (BD Vacutainer), and mononuclear cells were isolated by Ficoll density centrifugation. Normal pancreas tissue was collected from patients $(N=4)$ who were eligible for organ donation and had no malignant disease. Paraffin slides of normal human pancreas tissue $(N=5)$ were obtained from Abcam, GeneTex, IHC world, and Imgenex.

Pancreatic cancer tissue microarray survival analysis

After obtaining IRB approval, tissue microarray (TMA) studies were conducted on a cohort of 60 previously untreated patients with pancreatic ductal adenocarcinoma who underwent pancreaticoduodenectomy at Barnes-Jewish Hospital. Patients did not receive neo-adjuvant therapy and were typically treated with adjuvant chemotherapy. To construct the TMA, well-defined areas of tumor were demarcated and punched (1 $\mathrm{mm}$ diameter) from paraffin-embedded tumor blocks. An Aperio Scan-Scope XT Slide Scanner (Aperio Technologies) system was used to acquire digital images using a $20 \times$ objective. A tumor-specific nuclear algorithm (IHC-MARK) developed in-house [15] was modified to quantify CD14, CD8, and ALDH1 expression.

\section{STAT3 inhibitor}

STATTIC (STAT3 inhibitor V) was obtained from Calbiochem/EMD and used at doses less than the reported IC50 $(<20 \mu \mathrm{M})$ in vitro according to manufacturer instructions [21].

Cell lines

$\mathrm{KCM}$ and KCKO were a kind gift from Dr. Mukherjee [22], Panc-1 and BxPC3 were purchased from ATCC, and 
Pan02 [23], from the Division of Cancer Treatment Tumor Repository (NCI-Frederick Cancer Research and Development Center, Bethesda, MD).

\section{Animal husbandry}

$\mathrm{GCSFR}^{-1-}$ mice were a kind gift from Daniel C. Link (Internal Medicine/Division of Oncology). C57BL/6 and NU/J mice were purchased from Jackson Laboratories. Mice were maintained within the Washington University Laboratory for Animal Care barrier facility and all studies involving animals were approved by the Washington University School of Medicine Institutional Animal Studies Committee.

\section{Orthotopic model and preclinical animal cohorts}

Six- to eight-week-old $\mathrm{GCSFR}^{-1-}$ and wild-type (WT) mice were injected in the tail of the pancreas with $1 \times 10^{5}$ murine tumor cells suspended in $50 \mu 1$ of PBS and Matrigel (mixed 1:1). Mice were sacrificed at 31 days post-injection and peripheral blood, bone marrow, and tumors were collected. The bone marrow was extracted from femurs via high-speed centrifugation, and blood samples were collected in heparinized capillary tubes from retro-orbital sinus. Blood and bone marrow were washed once with sterile phosphate buffered saline (PBS) and subjected to red blood cell (RBC) lysis, according to manufacturer's instructions (RBC lysis buffer, Biolegend). We measured gross wet weight of orthotopic tumors. The tumors were minced into 2-3-mm-size pieces, mechanically dissociated using the Miltenyi Gentle-MACS tissue dissociator and digested in enzyme buffer that contained $1 \mathrm{mg} / \mathrm{ml} \mathrm{col-}$ lagenase, $2.5 \mathrm{U} / \mathrm{ml}$ hyaluronidase and $0.1 \mathrm{mg} / \mathrm{ml}$ of DNAse for $30 \mathrm{~min}$ at $37{ }^{\circ} \mathrm{C}$. Digestion mixtures were quenched by adding DMEM with $10 \%$ FBS and filtered through $70-\mu \mathrm{m}$ nylon strainers (BD falcon) and were counted. Pieces of tumor were also snap frozen in liquid nitrogen. Mice were injected with $2 \times 10^{5}$ tumor cells in $100 \mu$ l PBS subcutaneously, and tumor volume was calculated at specific time intervals by caliper measurements. We used 7-10 mice per group, and all these experiments were repeated in triplicate. All experiments were carried out according to animal studies committee guidelines.

\section{Flow cytometry}

Human and mouse single cell suspensions were blocked with TruStain FcX or anti CD16/32 antibody, respectively (Biolegend) and stained with fluorescent antibodies using standard protocols for flow cytometry. To stain ALDHBright cells, the Aldefluor assay was performed according to the manufacturer's protocol (Stem Cell Technologies).
For intracellular staining of cells, we used permeabilization buffer (eBioscience). We used CD45 (AF700; Biolegend, HI30), CD11b (AF488 and Pacific Blue; Biolegend, ICRF44), CD115 (PE; Biolegend, 9-4D21E4), CD14 (APC/Cy7; Biolegend, M5E2), CD15 (Pacific Blue; Biolegend, W6D3), CD68 (APC; Biolegend, CD68), HLA-DR (PE/Cy7; BIolegend, L243), CD4 (PerCP/Cy5.5; eBioscience, RPA-T4), CD8 (Pacific Blue; Biolegend, SK1), EpCAM (Pac Blue; Biolegend, 9C4), CD24(PE/Cy7; Biolegend, ML5), CD44 (APC/Cy7; Biolegend, IM7), and PPI (Biolegend) for human tumors. For mice, we used CD45 (APC/Cy7; Biolegend, 30-F11), CD11b (APC; Biolegend, M1/70), Ly6C (PE/Cy7; Biolegend HK1.4), Ly6G (Pacific Blue; Biolegend, 1A8), Gr-1 (AF700; Biolegend, RB6-865), F4/80 (PerCpCy5.5; Biolegend, BM8), I-A/IE (AF488; Biolegend, M5/114.15.2), CD4 (AF700; Biolegend, GK1.5), CD8a (PE; Biolegend, 53-6.7), ЕpCAM (PE/Cy7; Biolegend, G8.8), CD24 (PerCP/Cy5.5; Biolegend, M1/69), CD44 (APC/Cy7; Biolegend, IM7), and PPI(Biolegend). Data acquisition and analysis were performed using an LSRII system (BD Biosciences), Aria II High Speed Cell Sorter (BD Biosciences) for fluorescenceactivated cell sorting (FACS) and FlowJo version 7.6.5 software (Tree Star).

\section{RNA isolation and RT-PCR}

Snap-frozen tissue from mouse and human was homogenized in TRIzol Reagent (Life Technologies), and total RNA was isolated according to the manufacturer's guidelines. RNA samples were treated with DNAse (Promega), and the RNA was extracted with the RNeasy Mini Kit using the manufacturer's instructions for RNA clean up (Qiagen). RNA was reverse transcribed into cDNA using the high capacity RNA-to-cDNA kit (Life Technologies), and realtime PCR reactions were prepared by mixing cDNA with Taqman FAST universal PCR Master Mix and pre-designed Taqman Gene Expression assays (Life Technologies). Realtime PCR was performed on a 7500 FAST Thermal cycler (Applied Biosystems). Target gene expression was normalized to GAPDH, HPRT, or $\beta$-actin. Target gene expression was determined using the comparative $\mathrm{CT}\left(\Delta \Delta C_{\mathrm{T}}\right)$ method with 7500 software for 7500 RT-PCR system version 2.0.6 (Applied Biosystems).

CD8 suppression assays

PBMCs were isolated from healthy volunteers by Ficoll density centrifugation. $\mathrm{CD} 14^{+}$cells were isolated from the PBMCs of healthy volunteers with the EasySep ${ }^{\circledR}$ Human CD14 Positive Selection Kit according to the manufacturer's instructions (Stemcell Technologies ${ }^{\mathrm{TM}}$ ). $\mathrm{CD} 4^{+}$ cells were cocultured with BXPC 3 or Panc-1 tumor cells 
in a transwell plate to prevent cell to cell contact between the two populations. The $\mathrm{CD} 14^{+}$cells were mixed 1:1 with autologous PBMCs labeled with $10 \mu \mathrm{M}$ CFSE (Life Technologies) in 96-well round-bottom plates (Corning)

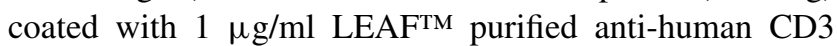
(Biolegend, clone OKT3) in complete media [RPMI containing $2 \mathrm{mM}$ glutamine, $100 \mathrm{U} / \mathrm{ml}$ penicillin, $100 \mu \mathrm{g} / \mathrm{ml}$ streptomycin, $1 \mathrm{mM}$ sodium pyruvate (Life Technologies), and $10 \%$ fetal bovine calf serum (Hyclone)] supplemented with $100 \mathrm{U} / \mathrm{ml}$ of human interleukin 2 (National Institute of Health). Cell cultures were harvested after $72 \mathrm{~h}$ at $37{ }^{\circ} \mathrm{C}$, and the CFSE dilution of the $\mathrm{CD} 4^{+}$and $\mathrm{CD} 8^{+} \mathrm{T}$ cell fractions was analyzed by flow cytometry.

In order to test the immunosuppressive properties of mouse Mo-MDSC, total mouse bone marrow was isolated from the femur and tibia of WT and G-CSFR ${ }^{-1-}$ mice by high-speed centrifugation. Bone marrow was subjected to $\mathrm{RBC}$ lysis in Tris lysing buffer $\left(144 \mathrm{mM} \mathrm{NH}_{4} \mathrm{Cl}, 17 \mathrm{mM}\right.$ Tris- $\mathrm{HCl}, \mathrm{pH} 7.2)$, and $\mathrm{CD}_{11} \mathrm{~b}^{+}$cells were isolated using the mouse CD11b positive selection kit according to the manufacturer's instructions (Stemcell Technologies). $\mathrm{CD}_{11 \mathrm{~b}^{+}}$cells were converted into Mo-MDSC by incubating in Pan02-conditioned medium for $72 \mathrm{~h}$ at $37{ }^{\circ} \mathrm{C}$ in 6-well flat-bottom plates. Tumor-conditioned media was prepared by incubating Pan02 in complete media in T75 flasks for $72 \mathrm{~h}$ at $37{ }^{\circ} \mathrm{C}$ followed by $0.2 \mu \mathrm{m}$ filtration. Single cell suspensions of mouse splenocytes were prepared by crushing the spleens of WT mice in PBS and filtering the suspensions over $40 \mu \mathrm{m}$ filters. Single cell suspensions were subjected to RBC lysis and splenocytes were labeled with CFSE as described above. Labeled splenocytes were cocultured in complete media supplemented with $50 \mu \mathrm{M}$ 2-mercaptoethanol in 96-well round-bottom plates (Corning) coated with $0.5 \mu \mathrm{g} / \mathrm{ml}$ LEAFTM $^{\mathrm{T}}$ purified anti-mouse CD3 (Biolegend, clone 145-2C11) and varying concentrations of $\mathrm{CD}_{11} \mathrm{~b}^{+}$cells previously treated with complete media alone or tumor-conditioned media. In some wells, arginase-1 activity was inhibited by adding nor-NOHA (Calbiochem) at a final concentration of $0.5 \mathrm{mM}$. Cell cultures were harvested after $72 \mathrm{~h}$ at $37{ }^{\circ} \mathrm{C}$, and the CFSE dilution of the $\mathrm{CD} 4^{+}$and $\mathrm{CD} 8^{+} \mathrm{T}$ cell fractions was analyzed by flow cytometry.

\section{Immunofluorescence}

Formalin-fixed paraffin-embedded tissue blocks of archived human pancreatic ductal adenocarcinoma were cut at $5 \mu \mathrm{m}$ using a Leica RM2235 microtome. Cut tissue sections were then floated onto SuperFrost Plus slides (Fisher Scientific) in a $42{ }^{\circ} \mathrm{C}$ water bath and dried overnight. Normal pancreas tissue previously cut and mounted on glass slides was purchased from Imgenex. Tissue sections were heated for $30 \mathrm{~min}$ at $65^{\circ} \mathrm{C}$ and deparaffinized in three changes of xylene. The sections were then rehydrated in serial changes in decreasing ethanol in deionized water $(100,95,70$, $50 \%$, then deionized $\mathrm{H}_{2} \mathrm{O}$ ) and rinsed in PBS. Tissue sections were submerged in citrate buffer $(10 \mathrm{mM}$ sodium citrate, $0.05 \%$ Tween 20, $\mathrm{pH}$ 6) or Target Retrieval Solution (DAKO, $\mathrm{pH}$ 9), and antigen retrieval was performed in a decloaking chamber (Biocare Medical). The sections were washed in running deionized water and rinsed in PBS. Tissue sections were then blocked for $30 \mathrm{~min}$ at room temperature in Serum-Free Protein Block (DAKO) and stained with primary antibodies diluted in Antibody Diluent (DAKO) overnight at $4{ }^{\circ} \mathrm{C}$. The following primary antibodies were used in this study: mouse anti-ALDH1, clone 44/ALDH (BD, 1:100); rabbit anti-CD11b, clone M1/70 (Abcam, 1:100); mouse anti-CD14 (Thermo Fisher Scientific Inc., 1:20); mouse anti-CD15, clone MY-1 (Abcam, 1:10); mouse anti-keratin 7, clone OV-TL 12/30 (Thermo Fisher Scientific, 1:50); and mouse anti-phospho-Stat3, clone D3A7 (Cell Signaling Technology, 1:400). Tissue sections were washed in PBS then stained with Alexa 488 goat antimouse IgG and Alexa 555 goat anti-rabbit IgG secondary antibodies (Life Technologies) diluted 1:200 in Antibody Diluent for $30 \mathrm{~min}$ at room temperature. TO-PRO-3 iodide (Life Technologies) was added to the secondary antibody cocktail at a final concentration of $1 \mu \mathrm{M}$ to visualize cellular nuclei. The tissue sections were washed in PBS, and then, the excess PBS was blotted off and sections were coverslipped with Vectashield Hard Mounting Media (Vector Labs). Confocal images were acquired on an Axiovert $100 \mathrm{M}$ microscope equipped with a LSM 510 META Confocal Laser Scanning Microscope system (Zeiss).

\section{Western blotting}

CD14 ${ }^{+}$cells previously cocultured with Panc-1 tumor cells (separated by a transwell insert) or cultured in complete media alone. After coculture, $\mathrm{CD} 14^{+}$cells were separated and washed with $1 \times$ PBS and lysed in RIPA buffer containing a protease inhibitor (Roche) and phosphatase inhibitor (Sigma) cocktails. Cell lysates were sonicated for $10 \mathrm{~s}$ then centrifuged at $4{ }^{\circ} \mathrm{C}$ for $10 \mathrm{~min}$ at $14,000 \times g$. The supernatant was removed and protein concentration was determined using a BCA Protein Assay kit (Lamda Biotech, Inc.,). Twenty microgram of total protein was prepared for denaturing gel electrophoresis under non-reducing conditions in NuPAGE ${ }^{\circledR}$ LDS buffer according to the manufacturer's instructions and loaded onto NuPAGE ${ }^{\circledR} 4-12 \%$ BisTris gels in an XCell SureLock Mini-Cell containing $1 \times$ NuPAGE $^{\circledR}$ MOPS SDS running buffer (Life Technologies). Gels were run at $200 \mathrm{~V}$ for $50 \mathrm{~min}$ and then blotted onto PVDF membranes in an XCell Surelock Mini-Cell by wet transfer with $1 \times$ NuPAGE transfer buffer (Life Technologies). After transfer, the blots were rinsed in washing buffer 
(TBST: $20 \mathrm{mM}$ Tris base, $137 \mathrm{mM} \mathrm{NaCl}, 0.1 \%$ Tween 20, pH 7.6) and blocked in blocking buffer (5\% non-fat dry milk in TBST) for $1 \mathrm{~h}$ at room temperature. The membranes were washed in TBST and incubated in rabbit antiphospho-STAT3 (Cell Signaling Technologies, clone D3A7; 1:2,000) or goat anti-actin (Santa Cruz Biotechnology, Inc., 1:200) primary antibodies diluted in TBST with $5 \%$ BSA overnight at $4{ }^{\circ} \mathrm{C}$. Membranes were washed in TBST and incubated in goat anti-rabbit IgG-HRP (Santa Cruz Biotechnology, Inc., 1:2,000) or donkey anti-goat IgG-HRP (Santa Cruz Biotechnology, Inc., 1:5,000) diluted in blocking buffer for $1 \mathrm{~h}$ at room temperature. The membranes were washed in TBST and protein bands were visualized with SuperSignal West Dura Extended Duration Substrate (Thermo Fisher Scientific). Blot images were acquired with a ChemiDoc XRS+ imaging system (Bio-Rad).

Invasion assays

BD BioCoat Matrigel Invasion chambers (Catalog\# 354480) were used to study the invasion of tumor cell lines cocultured with and without $\mathrm{CD} 11 \mathrm{~b}^{+}$or $\mathrm{CD} 14^{+}$cells. BD BioCoat chambers (24-well) were rehydrated using bicarbonate-based culture medium. $\mathrm{CD}_{11 \mathrm{~b}^{+}}$and $\mathrm{CD} 14^{+}$ cells were isolated from mice and humans, respectively, as described above and were plated in the bottom of 6-well chambers. The transwell inserts were placed in the chamber after $6 \mathrm{~h}$ of plating cells. Single cell suspensions of tumors (BxPC3, Panc-1, KCKO, KCM) were made in culture medium, and $2.5 \times 10^{4}$ tumor cells (in $0.5 \mathrm{ml}$ of culture medium) were added on top of the transwell insert to assess their ability to migrate/invade (downward) through the Matrigel-coated membrane. The cells were incubated in a humidified tissue culture incubator at $37{ }^{\circ} \mathrm{C}$ for $22 \mathrm{~h}$. The non-invading cells were removed from the upper surface of the membrane using a Q-tip. The cells that invaded through the Matrigel-coated membrane were then fixed using $100 \%$ methanol. After fixation, the cells that invaded through Matrigel membrane were stained using $1 \%$ toluidine blue (Sigma, Catalog\# 198161). The inserts were washed with $\mathrm{diH}_{2} \mathrm{O}$, air-dried, and membranes were removed from the inserts. The membranes were placed on a microscope slide with a small drop of immersion oil, and a cover slip was placed on top. Images of invaded cells were acquired under microscope at $40 \times$ magnification using SPOT RT digital camera and software. Cells were counted in six different fields of triplicate membranes.

Human and mouse bone marrow colony-forming unit (CFU) assay

Methylcellulose-based culture (MC) media (MethoCult, StemCell Technologies Catalog\# 03001) was thawed under refrigeration $\left(2-8{ }^{\circ} \mathrm{C}\right)$ overnight. Bone marrow cells were isolated from both human and mouse and were resuspended in PBS with $2 \% \mathrm{FBS}$ at $2 \times 10^{6}$ cells $/ \mathrm{ml}$. The cell suspension was added to Methocult medium at a 1:10 ratio to maintain correct medium viscosity. Three milliliter of the suspension was drawn and plated in a $35 \mathrm{~mm}$ low-adherence petri dish with a loose fitting lid. The petri dishes were placed in a large petri dish and incubated in a humidified tissue culture incubator at $37^{\circ} \mathrm{C}$ for 7 days. Granulocyte and macrophage colony-forming units (CFU-GM) were counted at $25 \times$ to $50 \times$ and a higher magnification was used to confirm CFU type. The comparison was made between PC patient bone marrow and healthy donor bone marrow. For mouse studies, the comparison was made between $\mathrm{GCSFR}^{-1-}$ and WT bone marrow.

Coculture experiments with transwell insert

All cocultures were performed using transwell inserts (BD Falcon Catalog\# 353090) so the tumor cells were separated from myeloid cells. CD14 $4^{+}$cells or $\mathrm{CD}_{11 b^{+}}$cells suspended in cell culture medium were plated on the 6-well cell culture plate (costar\# 3516). The transwell inserts were gently transferred into the previously filled wells (with $\mathrm{CD}_{11 \mathrm{~b}^{+}}$or $\mathrm{CD} 14^{+}$cells), and tumor cell suspension was added on top of the transwell insert. Tumor cells were isolated after coculture by removing the transwell inserts. CD $14^{+}$cells from the bottom were separately harvested. Isolated tumor cells and $\mathrm{CD} 14^{+}$cells were washed, and flow cytometry RT-PCR, and Western blotting were performed.

Statistical analysis

Graphpad prism V (Graphpad Software Inc.,) was used for statistical analysis. For nonparametric data Mann-Whitney test and for parametric data unpaired $t$ test was used $p<0.05$ was considered statistically significant.

\section{Results}

Pancreatic cancer is characterized by abundant granulocytic and monocytic myeloid cells as well as ALDH1 $1^{\text {Bright }}$ cancer stem cells

PC tumors possess a dense stroma characterized by abundant immunosuppressive myeloid cells [24]. However, myeloid cells are heterogeneous with different phenotypes. Therefore, we sought to better characterize these cells in human PC and found that both $\mathrm{CD} 14^{+}$(monocytic) and $\mathrm{CD}^{+} 5^{+}$(granulocytic) myeloid cells were 
highly prevalent by both flow cytometry analysis and immunofluorescence confocal microscopy (Fig. 1a, b). A significant population of $\mathrm{CD} 14^{+}$cells within the tumor had low HLA-DR expression by flow cytometry, a characteristic of Mo-MDSC (Fig. 1a). Unlike PC, however, normal human pancreas has significantly fewer number of $\mathrm{CD} 45^{+}$cells (including $\mathrm{CD} 14^{+}, \mathrm{CD} 15^{+}$myeloid infiltrate) compared with human PC (Fig. 1a, c; Supplementary figures 1,2).

We hypothesized that the high prevalence of MDSC in the tumor microenvironment was a result of enhanced myelopoiesis in the bone marrow of PC patients and active recruitment to the tumor. In order to study the effect of tumors on bone marrow myelopoiesis, we measured the myeloid progenitor cells by performing granulocyte macrophage colony-forming unit assays (CFU-GM) using bone marrow aspirates of $\mathrm{PC}$ patients and healthy controls. Indeed, bone marrow from PC patients formed significantly more CFU-GM compared to age-matched healthy controls (Fig. 1d). This suggests that tumors enhance myelopoiesis in the bone marrow of PC patients.

As previously stated, ALDH1 defines a subpopulation of treatment-resistant cancer cells with enhanced tumorinitiating properties in PC $[14,16]$. Our group previously reported that ALDH1 $1^{\text {Bright }}$ murine PC cells express higher levels of CD29, CD44, and CD49f, and we functionally characterized this population of cells by both in vitro spheroid assays and in vivo tumorigenic potential in nude mice. We also demonstrated that enrichment of ALDH1 $1^{\text {Bright }}$ cells promotes chemoresistance in PC [15]. Here, we performed flow cytometry and immunofluorescence staining and found that ALDH $1^{\text {Bright }}$ CSCs [identified as $\mathrm{CD}^{-} 5^{-}, \mathrm{EpCAM}^{+}$and propidium iodide (PI) $\left.{ }^{-}\right]$ composed roughly 6-10\% of tumor cells (Fig. 1e) compared to normal human pancreas (Supplementary figure 3).

To understand the clinical implications of the $\mathrm{CD} 14^{+}$cell infiltrate, we analyzed a tissue TMA from 60 PC patients. Tumors were scored for the presence of $\mathrm{CD} 14^{+}$and leukocytes and stratified into four groups $\left(\mathrm{CD} 14^{\mathrm{Hi}} / \mathrm{CD} 8^{\mathrm{Low}}\right.$, $\mathrm{CD} 14^{\mathrm{Low}} / \mathrm{CD} 8^{\mathrm{Low}}, \mathrm{CD} 14^{\mathrm{Hi}} / \mathrm{CD} 8^{\mathrm{Hi}}$, and $\mathrm{CD} 14^{\mathrm{Low}} / \mathrm{CD} 8^{\mathrm{Hi}}$ ). We observed that patients with predominant $\mathrm{CD}^{+} 4^{+}$/ $\mathrm{CD} 8^{\text {Low }}$ infiltrate in the tumor had a significantly reduced overall survival compared to all other groups (denoted as $\mathrm{CD} 14^{\mathrm{Low}} / \mathrm{CD} 8^{\mathrm{Low}}, \mathrm{CD} 14^{\mathrm{Hi}} / \mathrm{CD} 8^{\mathrm{Hi}}$, and $\mathrm{CD} 14^{\mathrm{Low}} / \mathrm{CD} 8^{\mathrm{Hi}}$, $p$ value $<0.001$ ) (Fig. 1f). Further analysis showed that $\mathrm{CD} 14^{+}$leukocytes correlated with tumor ALDH1 expression (Spearman's $r=0.2, p=0.02$ ) and tumors classified as $\mathrm{CD} 14^{\mathrm{Hi}}$ had increased ALDH1 ${ }^{\text {Bright }}$ cells (Supplementary figure 4). This led us to examine the link between the abundant MDSC infiltrate and the ALDH1 $1^{\text {Bright }}$ CSC sub population, which is a well-established cancer stem cell population in murine PC model [15].
$\mathrm{GCSFR}^{-/-}$mice with pancreatic cancer exhibit impaired myelopoiesis

To further study the potential relationship between tumorinduced bone marrow myelopoiesis and increased ALD$\mathrm{H} 1^{\text {Bright }} \mathrm{CSCs}$ in tumors, we employed a mouse model. Granulocyte colony-stimulating factor (G-CSF/CSF-3) is a critical growth factor for myeloid cell production in the bone marrow $[25,26]$. We utilized a G-CSF receptor knock out $\left(\mathrm{GCSFR}^{-l-}\right.$ ) mouse model (on a C57BL/6 genetic background) to study the effects of myelopoiesis in PC. These mice are unique in that they cannot increase myelopoiesis in response to physiologic triggers, including tumors [25, 27]. We utilized three distinct murine PC cell lines, denoted as $\mathrm{KCM}, \mathrm{KCKO}$, and Pan02, derived from spontaneous $\mathrm{PC}$ arising from genetic models (LSL-KRAS ${ }^{\mathrm{G} 12 \mathrm{D}} \times \mathrm{P} 48$ Cre $\times$ MUC1 and LSL-KRAS ${ }^{\mathrm{G} 12 \mathrm{D}} \times \mathrm{p} 48-\mathrm{Cre}$, respectively) or tumors arising from 3-methylcholanthrene carcinogenesis (Pan02) [23]. We implanted tumor cells subcutaneously in WT and $\mathrm{GCSFR}^{-/-}$mice and isolated bone marrow from both tumor bearing and non tumor bearing mice. Tumor bearing $\mathrm{GCSFR}^{-/-}$mice had significantly less CFU-GM as compared to WT mice ex vivo (Fig. 2a). Similar to PC patients, we observed an increase in bone marrow myelopoiesis and $\operatorname{MDSC}\left(\mathrm{CD} 11 \mathrm{~b}^{+}, \mathrm{Gr}^{+}\right)$in the peripheral blood of tumor-bearing WT mice [7]. In vivo, $\mathrm{GCSFR}^{-1-}$ mice were not able to upregulate myelopoiesis in response to $\mathrm{PC}$ implantation, which translated into significantly reduced G-MDSC and Mo-MDSC in the blood of tumor-bearing mice (Fig. 2b). However, MDSC from tumor-bearing WT and $\mathrm{GCSFR}^{-1-}$ mice were similarly immunosuppressive ex vivo (Supplementary figure 5). We have studied the direct ligand-receptor expression and identified that tumor cells do not express GCSF receptor (data not shown). This suggests that while $\mathrm{GCSFR}^{-1-}$ mice have reduced myelopoiesis, their myeloid cells retain immunosuppressive properties, thus meeting the definition of MDSC [28].

MDSC reduction alters the tumor microenvironment and correlates with decreased frequency of ALDH $1^{\text {Bright }}$ CSCs in murine pancreatic cancer

Because PC is characterized by an abundant stroma where myeloid cells predominate, we sought to determine the relationship between MDSC and ALDH1 ${ }^{\text {Bright }}$ CSCs using the $\mathrm{GCSFR}^{-1-}$ mouse model. GCSFR ${ }^{-1-}$ mice have significantly decreased tumor-infiltrating G-MDSC and Mo-MDSC, compared to WT tumors. In addition, there was a corresponding increase in tumor-infiltrating $\mathrm{CD} 8^{+} \mathrm{T}$ cell infiltrate while $\mathrm{CD} 4^{+} \mathrm{T}$ cells and macrophages (defined as $\mathrm{CD} 45^{+} / \mathrm{CD} 11 \mathrm{~b}^{+} /$ F4 $/ 80^{\text {hi }} / \mathrm{Ly}_{6 \mathrm{C}}{ }^{\text {low }} / \mathrm{MHCII}^{+}$) were unchanged (Fig. 2c). The bar graph shows infiltrating tumor cells as a percentage of 
A NORMAL HUMAN

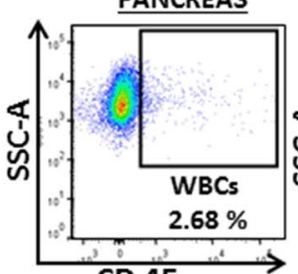

CD 45
HUMAN PANCREAS

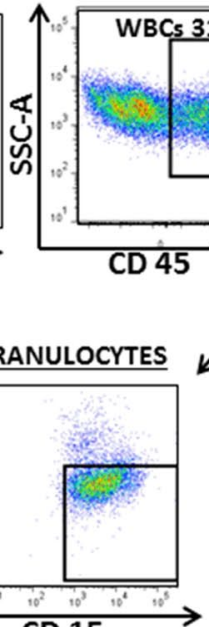

CANCER

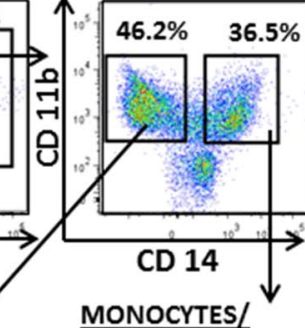

MACROPHAGES

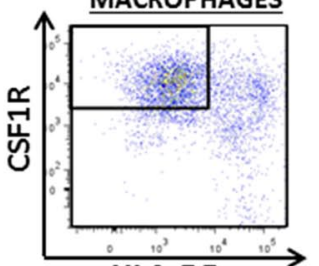

HLA-DR
B

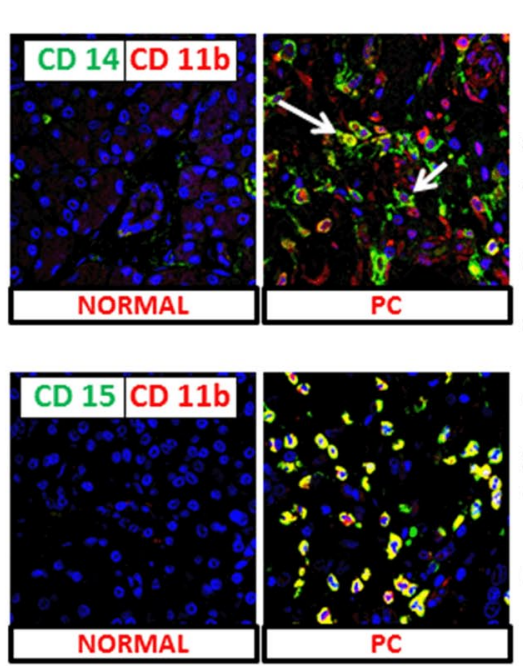

C

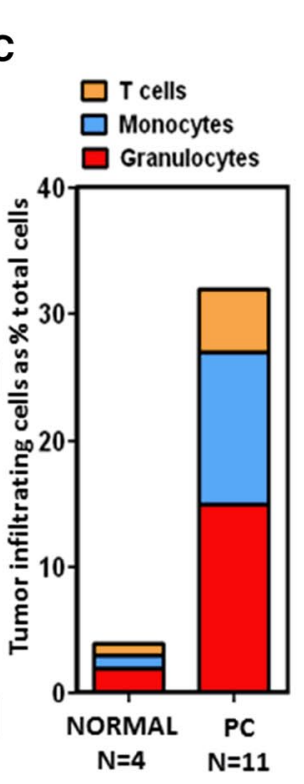

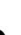

D

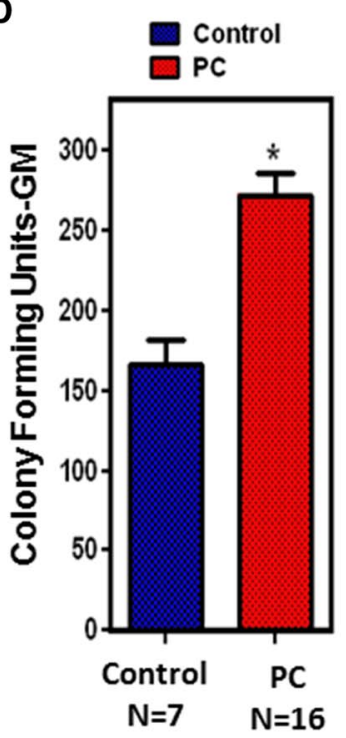

E

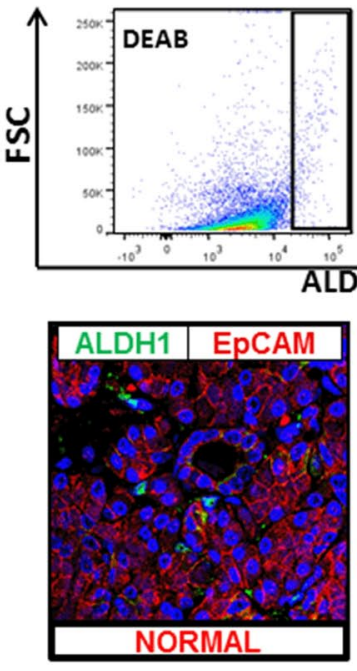

$\mathbf{F}$
Fig. 1 Myeloid cells and ALDH1 ${ }^{\text {Bright }}$ cells are prevalent in PC. a Flow cytometry performed on human PC samples $(N=11)$ and normal human pancreas $(N=4)$. Representative flow cytometry plot of normal human pancreas and PC tumor compares $\mathrm{CD} 45^{+}$infiltrate. Flow cytometry plots gating on $\mathrm{CD} 45^{+}$cells shows $\mathrm{CD} 14^{+}$and $\mathrm{CD} 15^{+}$infiltrate in the tumor. A significant population of $\mathrm{CD} 14^{+}$cells is HLA-DR ${ }^{\text {low/- }}$. A representative flow plot shows $2.68 \% \mathrm{CD}^{+} 5^{+}$cells infiltrating the normal human pancreas (gating is performed using isotype control). b Immunofluorescent staining was performed on normal human pancreas samples $(N=5)$ and PC samples $(N=5)$. Representative immunofluorescent confocal images $(\times 63)$ of normal human pancreas and $\mathrm{PC}$ stained for (CD11b, CD14), (CD11b, CD15). Green CD14 or CD15, red CD11b and blue Topro. c A histogram reporting percentages (average values) of the monocytic and granulocytic myeloid cells and T cells infiltrating the tumor as a percentage of total cells in PC tissue $(N=11)$ compared to normal human pancreas $(N=4)$. Granulocytes (normal pancreas $($ mean $\pm \mathrm{SD})=1.87 \pm 0.5$ and $\mathrm{PC}=14.6 \pm 0.65, p$ value $<0.05)$ and monocytes (normal $=1.3 \pm 0.7$ and $\mathrm{PC}=12.4 \pm 1.07, p$ value $<0.05$ ) are significantly increased in PC. d Upregulation of myelopoiesis in human PC; bone marrow specimens were collected from PC patients $(N=16)$ and age-matched healthy controls $(N=7)$; methylcellulose- based colony-forming unit assays were performed as described in "Materials and methods" section and were scored for the total number of myeloid colonies (CFU-GM) after 8 days. Bar graph depicts mean \pm SEM and asterisk denotes statistically significant difference between the two groups $p<0.05$ by Mann-Whitney test. e ALDH1 activity in human PC $(N=11)$; representative flow cytometry plot of human PC tumor gated on live $\mathrm{EpCAM}^{+}$cells using Aldefluor assay. Immunofluorescent staining was performed on PC samples $(N=5)$ and normal human pancreas samples $(N=5)$. Representative immunofluorescence confocal images $(\times 63)$ of normal human pancreas and PC stained for EpCAM, ALDH1 (green ALDH1, red EpCAM and blue Topro). Arrows point toward ducts expressing ALDH1 activity. $\mathbf{f}$ The CD14-CD8 ratio predicts PC patient survival. Automated analysis of $\mathrm{CD} 14^{+}$and $\mathrm{CD} 8^{+} \mathrm{IHC}$ reveals the relationship between leukocyte density and overall survival. The KaplanMeier estimate of overall survival comparing $\mathrm{CD} 14^{\mathrm{Hi}} / \mathrm{CD} 8^{\mathrm{Low}}, \mathrm{CD} 14^{\mathrm{Low}} /$ $\mathrm{CD} 8^{\mathrm{Low}}, \mathrm{CD} 14^{\mathrm{Hi}} / \mathrm{CD} 8^{\mathrm{Hi}}$, and $\mathrm{CD} 68^{\mathrm{Low}} / \mathrm{CD} 8^{\mathrm{High}}$, is shown. Patients with predominant $\mathrm{CD} 14^{+} / \mathrm{CD} 8^{\mathrm{Low}}$ infiltrate in the tumor had a significantly reduced overall survival compared to all other groups (denoted as $\mathrm{CD} 14^{\mathrm{Low}} / \mathrm{CD} 8^{\mathrm{Low}}, \mathrm{CD} 14^{\mathrm{Hi}} / \mathrm{CD} 8^{\mathrm{Hi}}$, and $\left.\mathrm{CD} 14^{\mathrm{Low}} / \mathrm{CD} 8^{\mathrm{Hi}}\right)$. There is a statistically significant difference between $\mathrm{CD} 14^{\mathrm{Hi}} / \mathrm{CD} 8^{\mathrm{Low}}$ and $\mathrm{CD} 14^{\mathrm{Low}} /$ $\mathrm{CD} 8^{\mathrm{Hi}}, p$ value $<0.001$ 


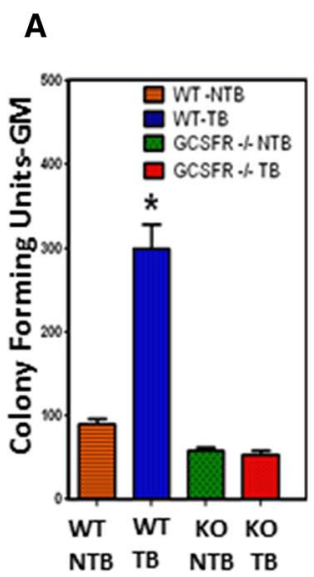

B

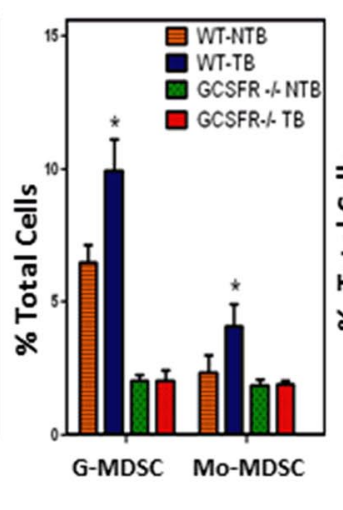

C

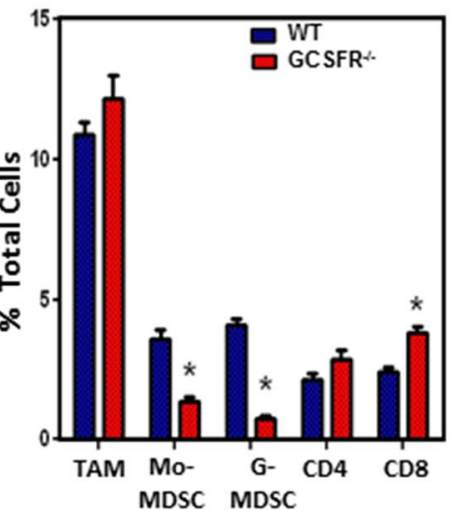

D

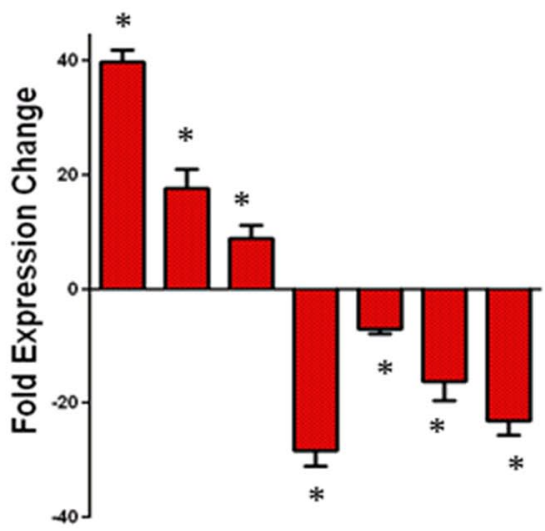

$\underline{\text { IFNV }} \frac{\text { TNF IL12 }}{\underline{\mathrm{a}}} \underline{\text { ARG1 }} \frac{\text { TGF }}{\underline{\beta}} \underline{\text { IL10 }} \underline{\text { IL6 }}$
E

\section{DEAB}
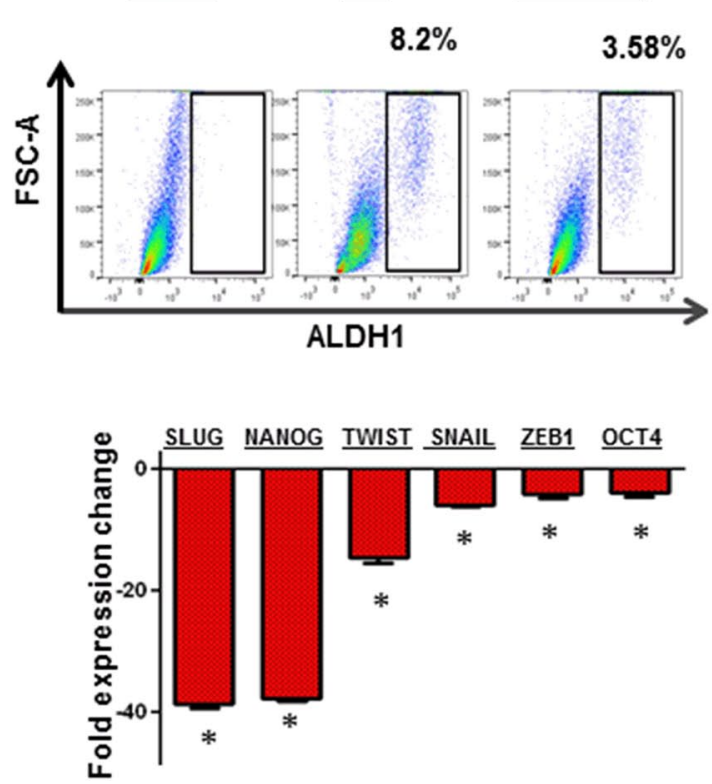

$\mathbf{F}$

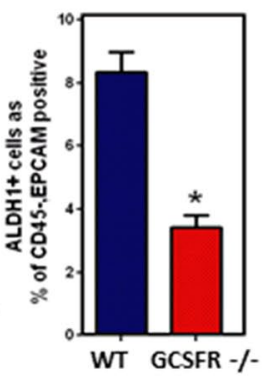

Tumor Growth curve

$\underline{\text { Tumor Weight }}$

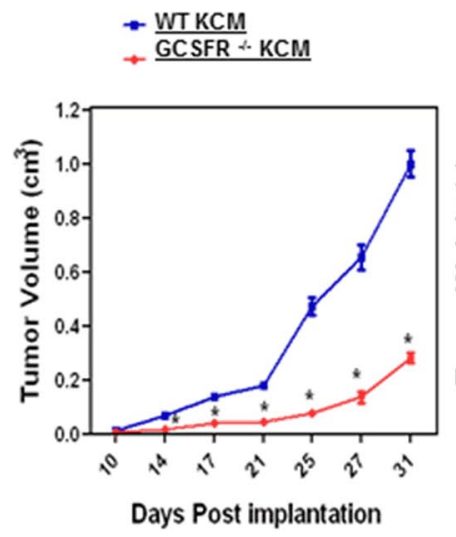

Fig. 2 Myeloid cells promote CSCs and EMT in murine PC. a CFU-GM in bone marrow; bone marrow was isolated from tumorbearing and non-tumor-bearing WT and $\mathrm{GCSFR}^{-1-}$ mice $(N=7-10$ mice/group), methylcellulose-based colony-forming unit assays were performed and scored for total number of myeloid (CFUGM) colonies after 8 days. Tumor-bearing WT mice have significantly increased myeloid colonies (CFU-GM) as compared to non-tumor-bearing WT mice. $\mathrm{GCSFR}^{-1-}$ mice have significantly decreased CFU-GM as compared to non-tumor-bearing WT mice ( $N T B$ non-tumor-bearing, $T B$ tumor-bearing). b Peripheral blood G-MDSC $\left(\mathrm{CD} 11 b^{+} / \mathrm{Gr}^{+} / \mathrm{Ly} 6 \mathrm{G}^{+} / \mathrm{Ly} 6 \mathrm{C}^{\mathrm{mid}}\right)$ and Mo-MDSC $\left(\mathrm{CD} 11 \mathrm{~b}^{+} / \mathrm{Gr}^{+} / \mathrm{Ly} 6 \mathrm{G}^{-} / \mathrm{Ly} 6 \mathrm{C}^{\mathrm{hi}}\right)$ calculated as a percentage of total cells. Data are shown for NTB and TB WT and GCSFR $^{-1-}$ mice. c Analysis compares tumor myeloid and lymphoid infiltrate by flow cytometry in WT and $\mathrm{GCSFR}^{-/-}$, KCM tumor-bearing mice. Mo-

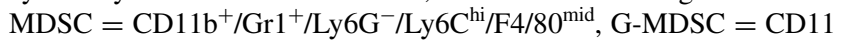

$\mathrm{b}^{+} / \mathrm{Gr}^{+} / \mathrm{Ly} 6 \mathrm{G}^{+} / \mathrm{Ly} 6 \mathrm{C}^{\mathrm{mid}}, \mathrm{T}$ cells $=\mathrm{CD} 45^{+} / \mathrm{CD}^{+} / \mathrm{CD}^{+}$, or $\mathrm{CD} 8^{+}$, $\mathrm{TAM}=\mathrm{CD} 45^{+} / \mathrm{CD} 11 \mathrm{~b}^{+} / \mathrm{F} 4 / 80^{\mathrm{hi}} / \mathrm{Ly} 6 \mathrm{C}^{\mathrm{low}} / \mathrm{MHCII}^{+}$. d Bar graph shows fold gene expression change in $\mathrm{GCSFR}^{-1-}$ tumors relative to WT tumors. e Representative flow cytometry plot showing mouse orthotopic PC specimens stained for ALDH1 activity. Analysis by flow cytometry demonstrated approximately $8.2 \% \mathrm{ALDH} 1^{\text {Bright }}$ CSCs in WT tumors and $3.58 \%$ in $\mathrm{GCSFR}^{-1-}$ tumors. Bar graph shows fold gene expression of Slug, Nanog, Twist, Snail, ZEB-1, and OCT-4 in GCSFR ${ }^{-1-}$ tumors relative to WT tumors. f Tumor growth curves comparing subcutaneous tumor growth, KCM by caliper measurements in WT mice and $\mathrm{GCSFR}^{-1-}$ mice. Points on curve represent mean values \pm SEM at indicated time points. Bar graph compares tumor weights of orthotopically implanted KCM in WT and $\mathrm{GCSFR}^{-/-}$mice 31 days post-injection. It depicts mean $\pm \mathrm{SEM}$ and asterisk denotes statistically significant difference between the two groups $p<0.05$ by Mann-Whitney test 
total cells. We also compared the tumor infiltrate in WT tumors that had different volumes $\left(0.4\right.$ and $\left.1.0 \mathrm{~cm}^{3}\right)$ to rule out the possibility that the differences in the G-MDSC and Mo-MDSC infiltrate are due to different tumor sizes (Supplementary figure $6 \mathrm{D}$ ). Furthermore, $\mathrm{GCSFR}^{-1-}$ mice exhibit a shift in the immune profile of PC tumors from a TH-2 to TH-1 immune response, characterized by increased expression of IFN- $\gamma$, TNF- $\alpha$ and IL-12 with decreased expression of arginase-1, IL-6, TGF- $\beta$, IL-10 compared to WT mice (Fig. 2d). Interestingly, tumors from $\mathrm{GCSFR}^{-/-}$ mice had significantly reduced ALDH $1{ }^{\text {Bright }} \mathrm{CSC}$ compared to those from WT mice (Fig. 2e). $\mathrm{GCSFR}^{-1-}$ tumors also displayed decreased expression of genes associated with cell pluripotency (i.e. Oct-4 and Nanog) and EMT (i.e. Snail, Slug, Twist and Zeb-1 by RT-PCR) (Fig. 2e). This suggests that the absence of MDSC in $\mathrm{GCSFR}^{-/-}$tumors is associated with a decrease in ALDH $1{ }^{\text {Bright }}$ CSCs.

Ultimately, this was associated with significantly decreased tumor growth in both subcutaneous and orthotopic PC tumors in $\mathrm{GCSFR}^{-1-}$ mice (Fig. 2f). These findings suggest an enhanced antitumor immune response in $\mathrm{GCSFR}^{-1-}$ mice is associated with reduced bone marrow-derived MDSC in the tumor. Similar results were found using other murine PC cell lines (Supplementary figure $6 \mathrm{~A}-\mathrm{C})$.

Monocytic MDSC directly increase the frequency of $\mathrm{ALDH} 11^{\text {Bright }} \mathrm{CSCs}$ in murine PC

Since decreased tumor-infiltrating MDSC were associated with reduced ALDH $1^{\text {Bright }} \mathrm{CSCs}$, we hypothesized that MDSC contribute to expanding the population of ALD$\mathrm{H} 1^{\text {Bright }}$ CSCs. To test this, we utilized an in vitro model utilizing murine cell lines in order to exclude the possibility of involvement of other cell types. We cocultured in vitro-maintained KCM with myeloid cells from the bone marrow of tumor-bearing mice (cells were separated by transwell insert). The frequency of ALDH $1^{\text {Bright }} \mathrm{CSCs}$ and $\mathrm{CD} 24^{+}, \mathrm{CD} 44^{+} \mathrm{CSC}$ s was significantly increased in $\mathrm{KCM}$ cocultured with $\mathrm{CD} 11 \mathrm{~b}^{+}$cells, compared to $\mathrm{KCM}$ alone (Fig. 3a). However, MDSC are composed of both MoMDSC and G-MDSC and perhaps only one of these two subsets were responsible for this observation. Therefore, we isolated Mo-MDSC and G-MDSC from the tumors of WT mice by FACS and cocultured these cells separately with KCM. We found that the frequency of ALDH1 $1^{\text {Bright }}$ CSCs was significantly increased when KCM was cocultured with Mo-MDSC while there was no increase with G-MDSC, separated by transwell insert (Fig. 3b). This suggests that Mo-MDSC enhance the ALDH $1^{\text {Bright }}$ and $\mathrm{CD} 24^{+}, \mathrm{CD}_{4} 4^{+} \mathrm{CSC}$ in PC. In order to validate this finding, we also cultured murine PC tumor cells for sphere formation after they were cocultured with myeloids. The spheres were harvested and then implanted subcutaneously in WT mice, and tumor growth was compared to non cocultured tumor cells. The tumors grew faster when the tumor spheres were implanted after coculture with myeloid cells compared to the spheres that were not cocultured with myeloid cells (Fig. 3c). We also assessed changes in the expression of markers promoting epithelial to mesenchymal transition and performed functional studies. The tumor cells were separated from Mo-MDSC after coculture, and RT-PCR and Western blotting were performed. There was downregulation of E-cadherin and upregulation of vimentin in the tumor cells that were previously cocultured (separated by a transwell insert) with myeloid cells (Fig. 3d). Invasion studies further supported that tumor cells that were previously cocultured with myeloid cells had a mesenchymal phenotype and significantly invaded the Matrigel plug compared to the tumor cells that were not cocultured with myeloid cells (Fig. 3e). This suggests that Mo-MDSC promote CSCs in murine PC and promote mesenchymal properties of tumor cells.

Human pancreatic cancer converts circulating monocytes into Mo-MDSC

In order to study the role of Mo-MDSC in human PC, we cocultured normal human blood monocytes with human PC cell lines (Panc-1 and BxPC3). The CD14 ${ }^{+}$cells were harvested and assessed by flow cytometry, immune suppression, RT-PCR, and Western blotting. These monocytes acquired a Mo-MDSC phenotype characterized by a significantly decreased expression of HLA-DR and increased expression of arginase- 1 as well as the ability to suppress $\mathrm{CD}^{+} \mathrm{T}$ cell proliferation in vitro [29-32] (Fig. 4a-c). See supplementary figure 7 for similar results using the BxPC3 cell line. Thus, tumor-derived factors in $\mathrm{PC}$ are capable of changing the phenotype and functionality of human blood monocytes, converting these cells into immunosuppressive Mo-MDSC. In PC patients with primary disease only, the $\mathrm{CD} 14^{+}$cells in the blood have a high HLA-DR expression but these cells only obtain MDSC phenotypic markers when they infiltrate the tumor (Fig. 4d).

Mo-MDSC promote stemness in human PC by a STAT3-dependent mechanism

Since Mo-MDSC in mice increase the prevalence of ALD$\mathrm{H} 1^{\text {Bright }} \mathrm{CSCs}$ and enhance expression of genes associated with EMT in murine PC, we sought to determine if the same phenomenon occurs in human PC. We generated MoMDSC in vitro as described above and cocultured these cells with PC cell lines in vitro. Both Mo-MDSC and tumor cells were analyzed by flow cytometry and RT-PCR after 
A

DEAB KCM alone KCM \& CD11 $b^{+}$cells
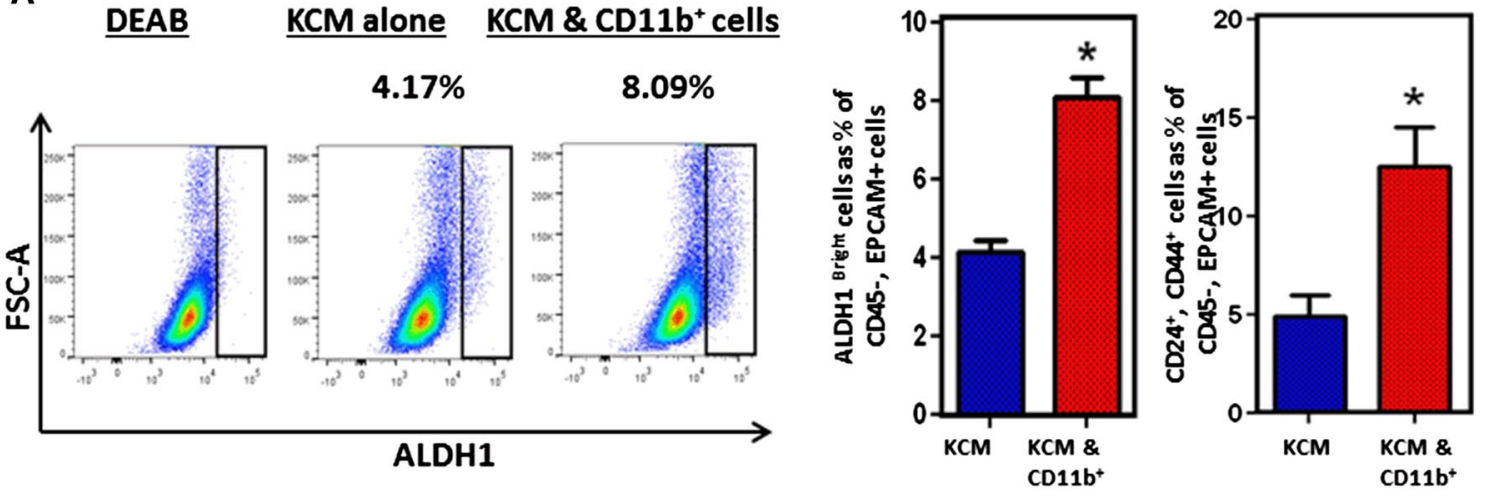

B
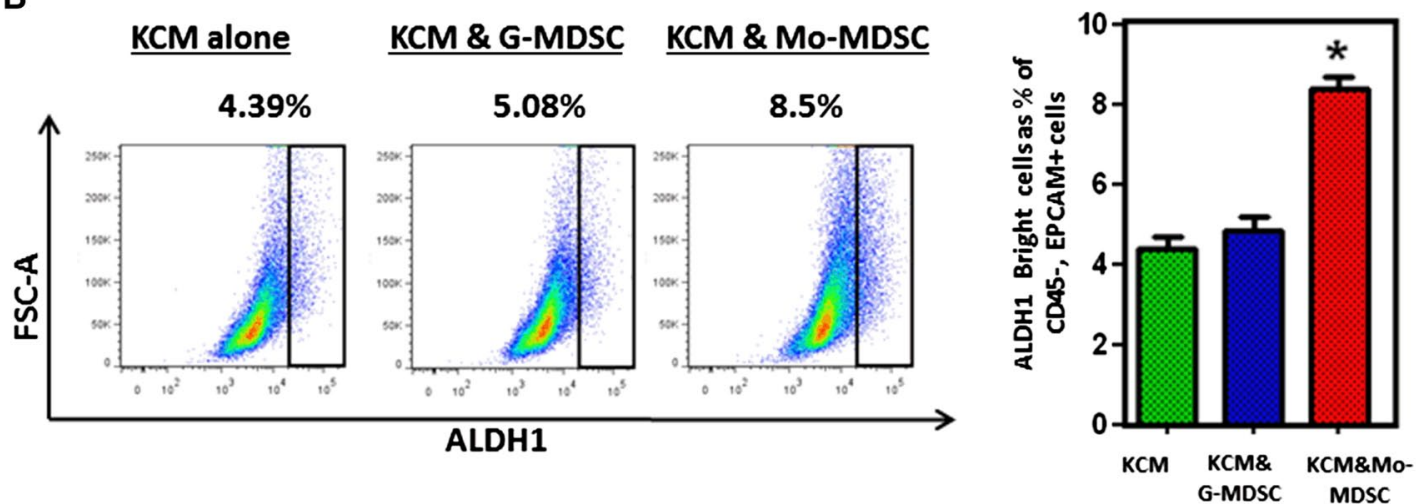

C

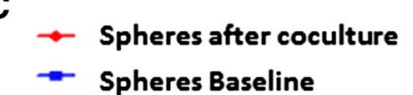

D

E
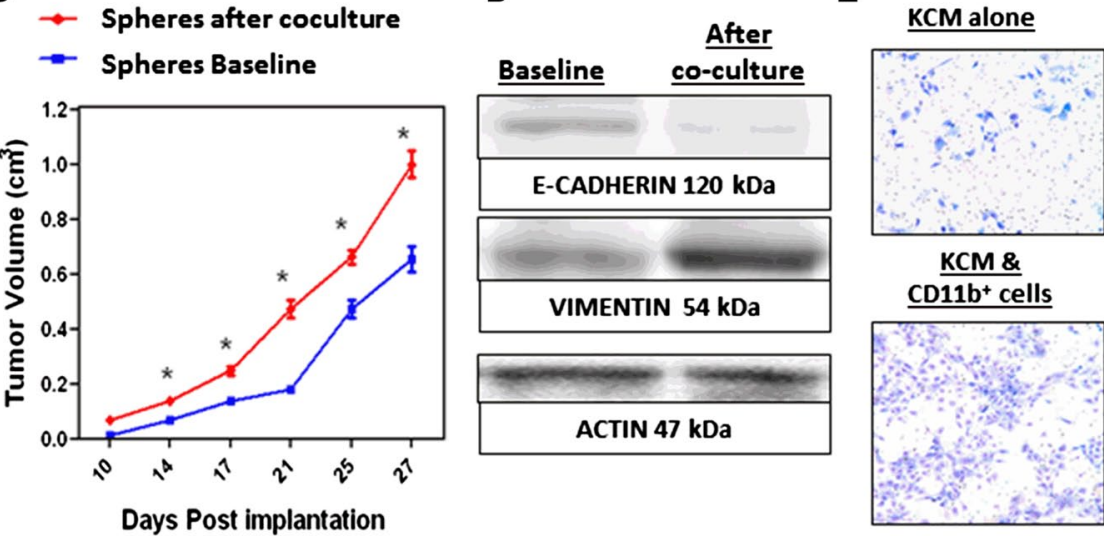

KCM \&

CD11b+cells
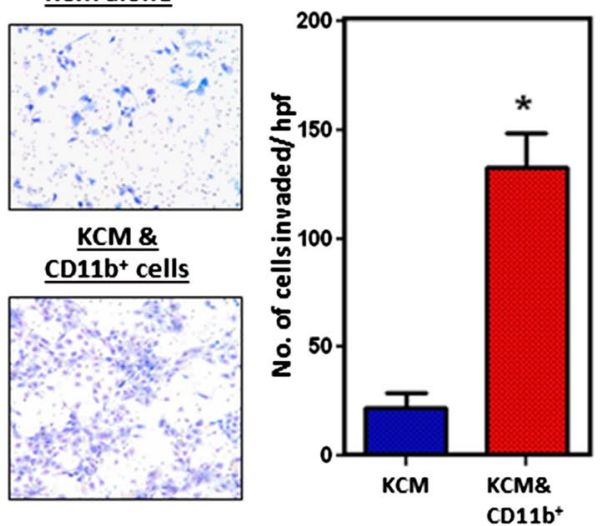

Fig. 3 a KCM cultured alone and with $\mathrm{CD}_{11} \mathrm{~b}^{+}$cells isolated from bone marrow of WT tumor-bearing mice by magnetic bead isolation, for $72 \mathrm{~h}$. KCM tumor cells were isolated and stained for ALDH1 activity and other CSC markers. Representative flow cytometry plots show ALDH1 $1^{\text {Bright }}$ CSCs, which constitute approximately $4.17 \%$ when $\mathrm{KCM}$ is cultured alone and increase up to $8.09 \%$ after coculture with $\mathrm{CD}_{11 \mathrm{~b}^{+}}$cells. Bar graph shows percentage $\mathrm{ALDH} 1^{\text {Bright }}$ and $\mathrm{CD} 24^{+}, \mathrm{CD} 44^{+}$cancer stem cells in KCM, with and without coculture with CD11b ${ }^{+}$cells. b G- and Mo-MDSC were isolated from orthotopically implanted KCM tumors of WT mice by FACS. These cells were separately cocultured with KCM for $72 \mathrm{~h}$. After $72 \mathrm{~h}, \mathrm{KCM}$ cells were isolated and stained for ALDH1 activity. Representative flow cytometry plots show that ALDH1 $1^{\text {Bright }}$ CSCs constitute approximately $4.39 \%$ when $\mathrm{KCM}$ is cultured alone, $5.08 \%$ when KCM cocultured with G-MDSC and increases up to $8.5 \%$ when KCM is cocultured with Mo-MDSC. $\mathbf{c}$ Tumor growth curves comparing subcutaneous tumor growth, KCM spheres (with baseline ALDH1 activity) and KCM spheres after coculture (increased ALDH1 activity) by caliper measurements in WT mice. Points on curve represent mean values \pm SEM at indicated time points. $\mathbf{d} C D 11 b^{+}$cells were isolated after coculture with tumor cells in transwell plates and were used for Western blotting. Western blot analysis of KCM shows downregulation of E-cadherin and upregulation of vimentin in KCM from baseline after coculture with $\mathrm{CD} 11 \mathrm{~b}^{+}$cells. e Invasion assays were performed to compare the invading properties of tumor cells. Tumor cells were seeded in the upper part of Matrigel-coated transwell inserts. Cell invasion index was calculated as the number of cells attached to the bottom of Matrigel-coated membrane. Figure shows that KCM tumor cells have increased invasion through Matrigel matrix membrane after coculture relative to tumor cells alone. Cells per high-power field were quantified. Cells were counted in six different fields of triplicate membranes. Graph depicts the number of invaded cells per high-powered field (mean \pm SEM of three independent experiments). Asterisks denotes statistically significant difference between the two groups $p<0.05$ by Mann-Whitney test. We used 7-10 mice per group and all these experiments were repeated in triplicate 

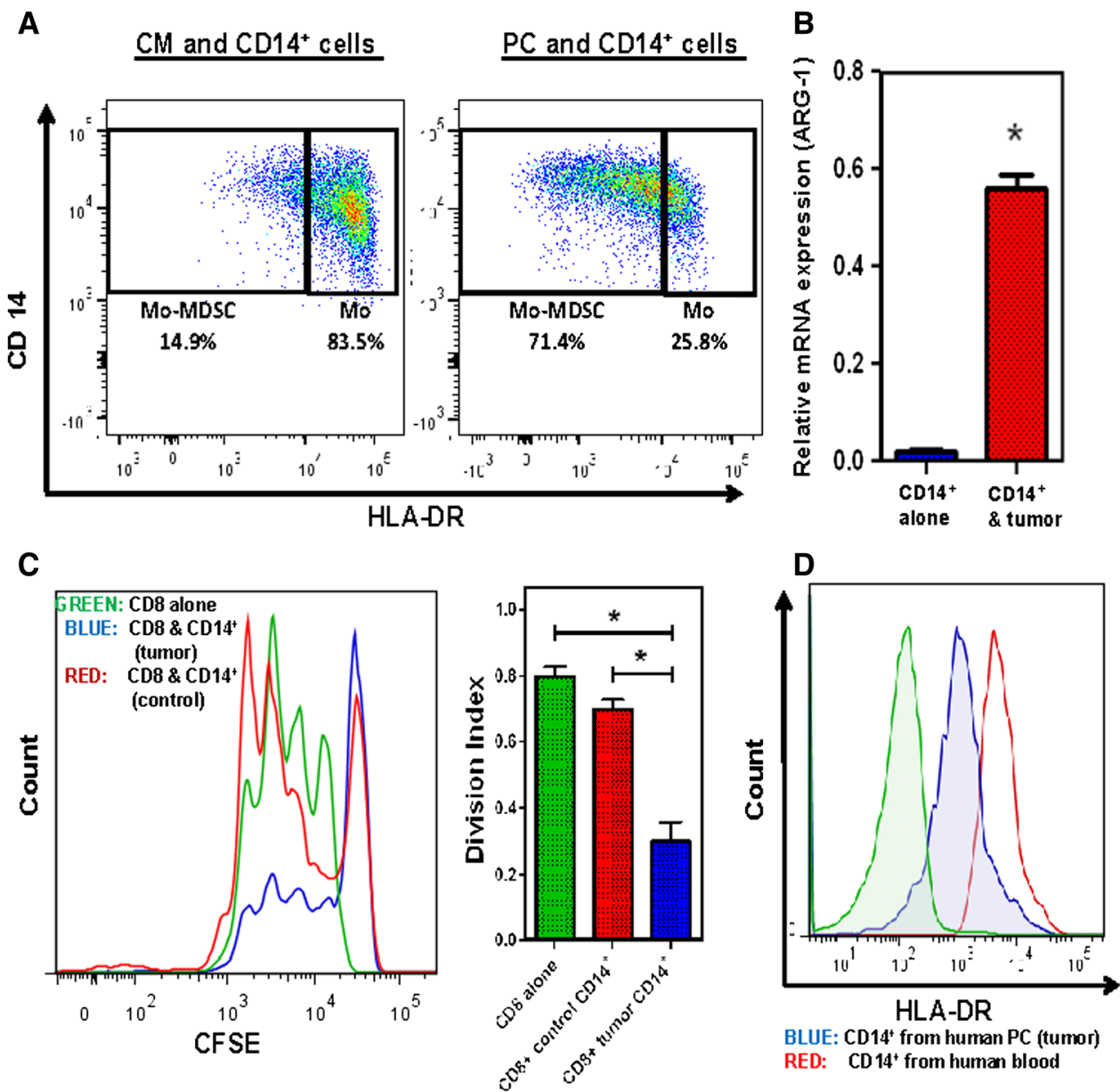

Fig. $4 \mathrm{CD}^{+} 4^{+}$cells were isolated from normal human PBMC by magnetic bead isolation and were cocultured with human PC cell line Panc-1 for $72 \mathrm{~h}$. a Downregulation of HLA-DR expression after tumor exposure; flow cytometry was performed on $\mathrm{CD} 14^{+}$cells (from blood) after $72 \mathrm{~h}$ of coculture with tumor cells. Representative plots show that approximately $83.5 \% \mathrm{CD} 14^{+}$cells had high HLADR expression when these cells are incubated in complete medium (CM). After tumor exposure, these cells downregulate HLA-DR expression and $71.4 \% \mathrm{CD} 14^{+}$cells have low HLA-DR expression. b Analysis of quantitative RT-PCR results for gene expression of argin-

coculture. Consistent with our findings in mice, Mo-MDSC increased the $\mathrm{ALDH} 11^{\text {Bright }}$ and $\mathrm{CD} 24^{+}, \mathrm{CD} 44^{+}$CSC population in $\mathrm{BxPC} 3$ after coculture as compared to control tumor cells (Fig. 5a). In order to validate this finding, we also cultured human PC tumor cells for sphere formation after they were cocultured with $\mathrm{CD} 14^{+}$cells. The spheres were isolated and implanted subcutaneously in NU/J mice and tumor growth was compared to non-cocultured tumor cells. The tumors grew faster when the tumor spheres were implanted after coculture with Mo-MDSC, compared to spheres that were not cocultured with Mo-MDSC (Supplementary figure 8). Consistent with enhanced tumor-initiating properties, we observed that the transcription factors ase- 1 from $\mathrm{CD}_{14}{ }^{+}$cells cocultured with and without tumor. Normalized fold change is depicted. c Representative flow cytometry histogram from $T$ cell suppression assay depicts stimulated, CFSE-labeled $\mathrm{CD}^{+} \mathrm{T}$ cells cocultured with tumor-conditioned or unconditioned $\mathrm{CD} 14^{+}$cells for $72 \mathrm{~h}$. d Representative flow cytometry plot shows differential expression of HLA-DR on $\mathrm{CD} 14^{+}$cells isolated from the blood and human tumor specimens. Bar graphs depict mean division index \pm SEM with asterisk denotes $p<0.05$ by Mann-Whitney in all panels

associated with cell pluripotency and EMT, i.e., Snail, Slug, Twist, Zeb-1, Nanog, and Oct-4 were significantly increased by RT-PCR in PC cells cocultured with MoMDSC. Invasion studies showed that the tumor cells that were previously cocultured with Mo-MDSC have significantly increased invasion activity (Fig. 5b). Similar results were seen using Panc-1 (Supplementary figure 9). This suggests that human Mo-MDSC promote tumor stemness and EMT. Additionally, we found that IL-6 expression was upregulated in the Mo-MDSC as compared to normal monocytes (Fig. 5c).

STAT3 activity in tumor cells has been demonstrated to facilitate the expansion and maintenance of CSCs in several 
A
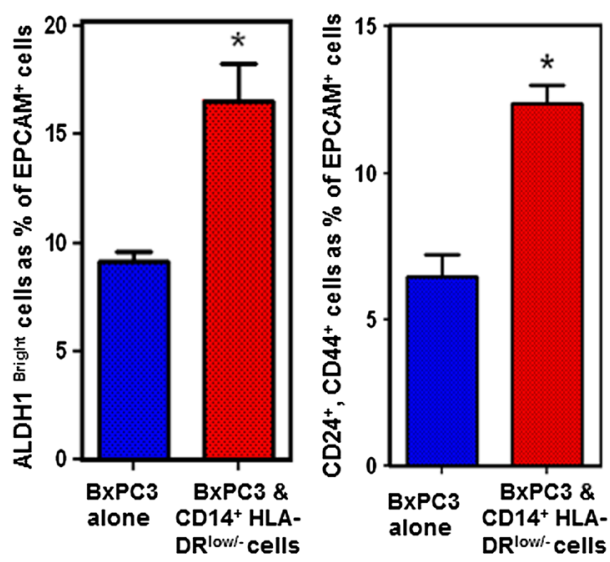

C

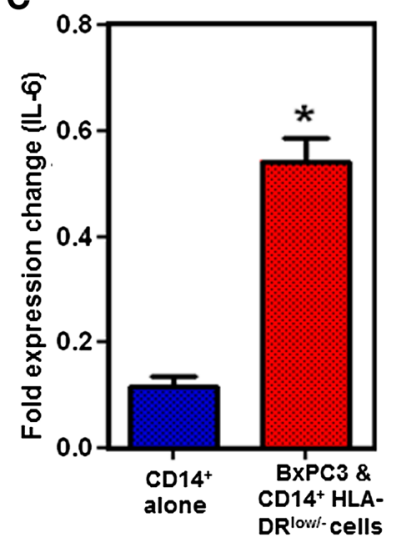

F
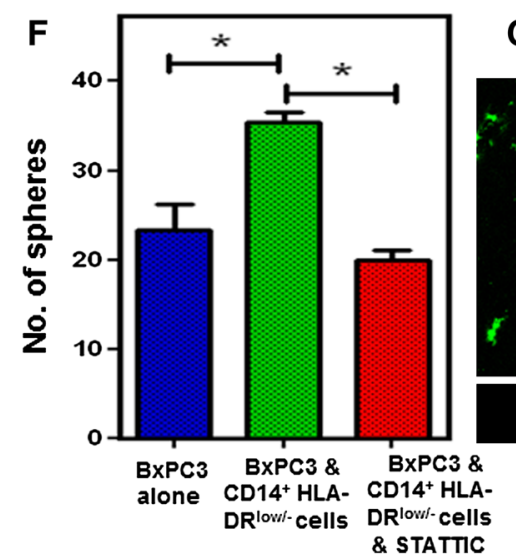

G

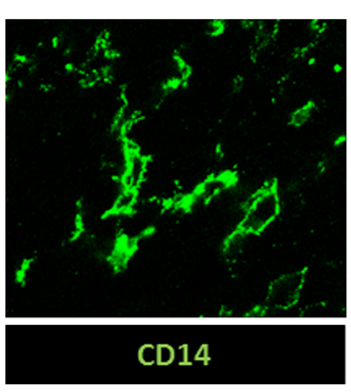

B

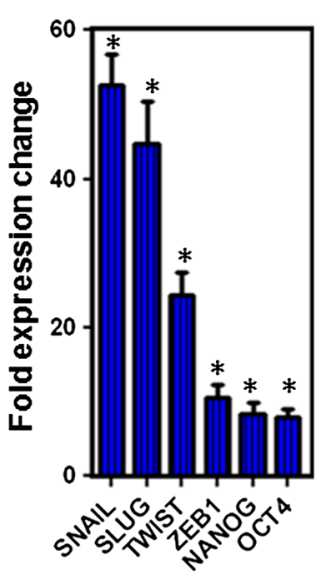

D
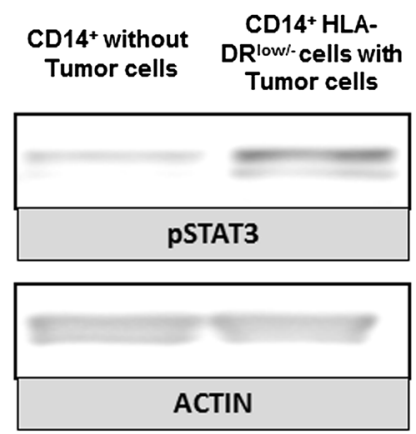
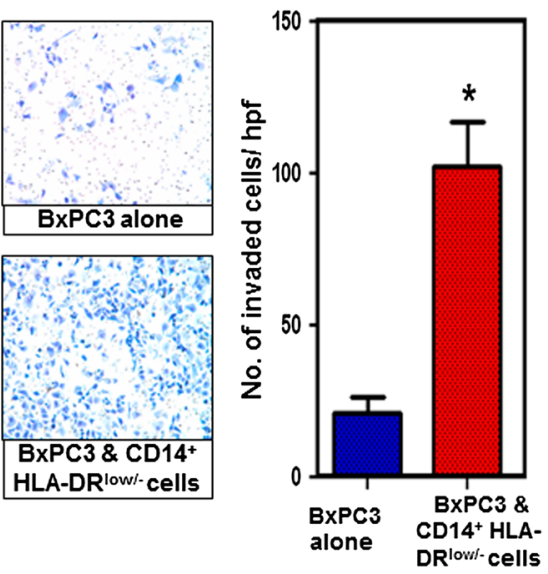

$\mathbf{E}$

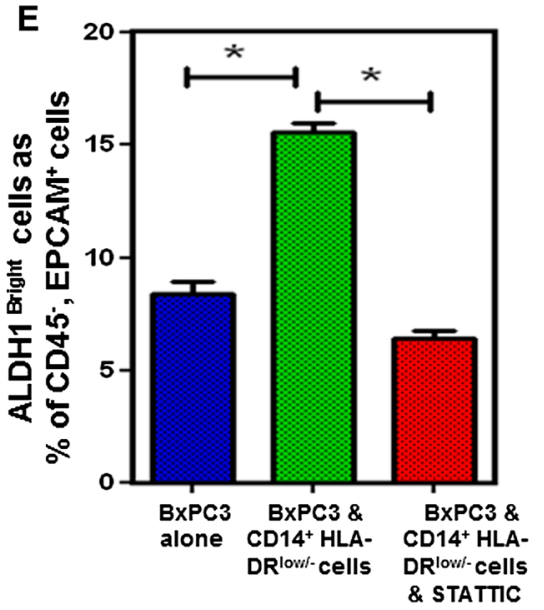

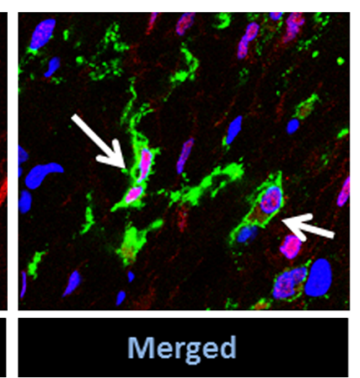

tumor types [17]. However, we hypothesized that up regulation of signal transducer and activator of transcription 3 (pSTAT3) in Mo-MDSC is involved in promoting ALDH$1^{\text {Bright }} \mathrm{CSCs}$ in $\mathrm{PC}$. $\mathrm{CD} 14^{+}$cells were isolated from tumor cells after coculture and Western blotting was performed. We observed that there was upregulation of phosphorylated STAT3 in tumor-treated CD14 ${ }^{+} / \mathrm{HLA}^{-D R^{\text {low/- }}}$ cells as compared to untreated $\mathrm{CD} 14^{+}$cells by Western blotting (Fig. 5d). We also found upregulation of pSTAT3 in
$\mathrm{CD}_{11 \mathrm{~b}^{+}}$cells after coculture with murine PC cell lines (Supplementary figure 10). In order to determine if pSTAT3 mediated the ability of Mo-MDSC to increase the prevalence of $\mathrm{ALDH} 1^{\text {Bright }} \mathrm{CSC}$, Mo-MDSC were treated with STATTIC, a small molecule inhibitor of STAT3 [21] and washed with PBS. STATTIC-treated cells were then plated in a 6-well plate, and a transwell insert was placed on top of the cells. Human PC tumor cells were added to the transwell insert and were cultured for $72 \mathrm{~h}$. We found that 
4 Fig. 5 STAT3 activity in Mo-MDSC promotes CSCs and EMT in PC. a CD14 ${ }^{+} / \mathrm{HLA}-\mathrm{DR}{ }^{\text {low/- }}$ cells were cocultured with $\mathrm{BxPC} 3$ for $72 \mathrm{~h}$ and ALDH1, CD24, and CD44 staining was performed. Graph shows $\mathrm{ALDH} 1{ }^{\text {Bright }} \mathrm{CSCs}$ and $\mathrm{CD} 24^{+}, \mathrm{CD} 44^{+}$cells as a percentage of $\mathrm{CD}_{4} 5^{-}, \mathrm{EpCAM}^{+}, \mathrm{PI}^{-}$cells. b Tumor EMT markers and invasion assay; RT-PCR shows that markers of cell pluripotency and EMT were upregulated in BxPC3 tumor cells after coculture with $\mathrm{CD}_{14}{ }^{+} / \mathrm{HLA}-\mathrm{DR}{ }^{\text {low/- }}$ cells. Invasion assays showing that $\mathrm{BxPC} 3$ tumor cells have increased invasion through Matrigel matrix membrane after coculture with $\mathrm{CD} 14^{+}$cells relative to tumor cells alone. Cells per high-power field were quantified. Graph depicts the number of invaded cells per high-powered field (mean \pm SEM of three independent experiments). c Analysis of quantitative RT-PCR results for expression of IL- 6 by $\mathrm{CD} 14^{+}$cells cocultured with and without BxPC3 tumor. Normalized fold change is depicted. d Western blot analysis of STAT3 phosphorylation in CD14 ${ }^{+}$cells cocultured with and without BxPC3 tumor cells for $72 \mathrm{~h}$. e Inhibition of STAT3 signaling in $\mathrm{CD}_{14} / \mathrm{HLA}-\mathrm{DR}^{\text {low/- }}$ cells prevents the increase in ALDH $1^{\text {Bright }} \mathrm{CSC}$ in $\mathrm{BxPC} 3$ from baseline. $\mathrm{CD} 14^{+}$cells treated with STATTIC were washed and then cocultured with tumor cells in transwell plates. Bar graph shows ALDH1 ${ }^{\text {Bright }}$ CSC population (gated on $\mathrm{CD}^{-} 5^{-}, \mathrm{EpCAM}^{+}, \mathrm{PI}^{-}$cells) which is approximately $8.79 \%$ in $\mathrm{BxPC} 3$ alone, $15.8 \%$ when $\mathrm{BxPC} 3$ was cocultured with $\mathrm{CD}^{+}{ }^{+} / \mathrm{HLA}_{-\mathrm{DR}}{ }^{\text {low/- }}$ cells and $6.02 \%$ when BxPC3 was cocultured with STATTIC-treated CD14 ${ }^{+} / \mathrm{HLA}^{-D R^{\text {low/- }}}$ cells. Graph shows that inhibition of STAT3 signaling by STATTIC $(20 \mu \mathrm{M})$ blocks the increase in frequency of ALDH $1^{\text {Bright }}$ cells from baseline. $\mathbf{f}$ Bar graph shows tumor spheroid formation in $\mathrm{BxPC} 3$ and Panc- 1 cells with and without $\mathrm{CD} 14^{+} / \mathrm{HLA}^{-D R^{\text {low }}-}$ cells in the coculture. The mean number of tumor spheroids formatted after 10 days is depicted. $\mathbf{g}$ Representative immunofluorescence confocal images $(\times 63)$ of human PC stained for $\mathrm{CD}_{14}{ }^{+}$cells and pSTAT3 activity. Green CD14 and red pSTAT3. Bar graphs depict mean division index \pm SEM with asterisk denotes $p<0.05$ by Mann-Whitney in all panels

treatment with STATTIC entirely prevented the Mo-MDSC mediated increase in ALDH $1{ }^{\text {Bright }}$ CSCs (Fig. 5e). In addition, we performed tumor sphere-forming assays, which display an increased tumor spheroid formation compared to control tumor cells in vitro, and treatment with STATTIC significantly decreased the Mo-MDSC mediated increase in sphere formation (Fig. 5f).

STAT3 signaling in MDSC can be modulated by IL-6 $[33,34]$, which has been shown to enhance CSCs and EMT in cancer. While we found that IL-6 mRNA gene expression was significantly downregulated by STAT3 inhibition (Supplementary figure 11), IL-6 blockade using anti-IL-6 antibodies decreased but did not fully reverse the effect of Mo-MDSC on increasing the prevalence of ALDH $1^{\text {Bright }}$ CSCs. This suggests that the effects of Mo-MDSC on promoting tumor stemness are likely mediated by multiple factors downstream of pSTAT3. Finally, to confirm that $\mathrm{CD} 14^{+}$cells express pSTAT3 in vivo, we performed immunofluorescence staining for CD14 and pSTAT3 in human PC. Indeed, the majority of $\mathrm{CD} 14^{+}$leukocytes in the tumor microenvironment expressed pSTAT3 (Fig. 5g). These data suggest that PSTAT3 positive Mo-MDSC play an important role in PC progression by enhancing the population of $\mathrm{ALDH} 11^{\text {Bright }} \mathrm{CSCs}$ and promoting EMT.

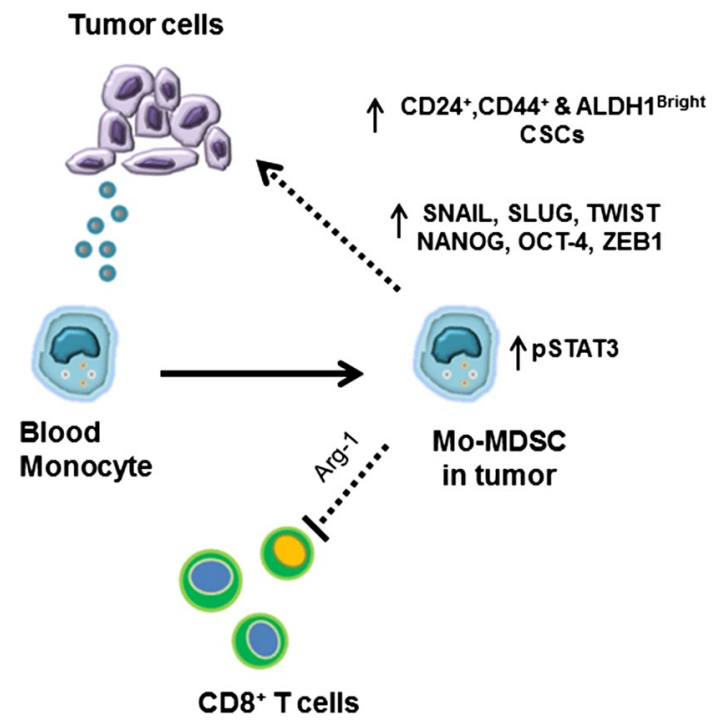

Fig. 6 Activation of pSTAT3 in the Mo-MDSC enhances the CSCs in the PC tumor

\section{Discussion}

$\mathrm{PC}$ is unique for its dense infiltrate of myeloid cells with a paucity of $\mathrm{T}$ cells. Myeloid recruitment is critical to the establishment and progression of PC. Tumors communicate with the bone marrow to increase myelopoiesis in both tumor-bearing mice and human PC patients. These myeloid cells are then recruited to the tumor microenvironment where they enhance growth and metastasis. In this study, we demonstrate the importance of MDSC on promoting the ALDH $1{ }^{\text {Bright }} \mathrm{CSCs}$ in PC tumors. In our $\mathrm{GCSFR}^{-l-}$ mouse model, we found that the reduction in MDSC in the tumor decreases the ALDH $1^{\text {Bright }}$ CSC population. We also found that the expression of EMT markers and stem cell genes were downregulated in the tumors of $\mathrm{GCSFR}^{-1-}$ mice. We further demonstrate that Mo-MDSC in human PC promote cancer stemness in a STAT3-dependent manner.

In our experiments, we found that monocytes can become Mo-MDSC, as they downregulate HLA-DR expression and suppress $\mathrm{T}$ cell proliferation in the presence of tumor cells or tumor-derived factors (Fig. 6). This is important as it suggests that even mature human monocytes can acquire immunosuppressive properties upon exposure to tumor-derived factors. We have previously demonstrated that increased peripheral blood monocyte counts correlate with decreased survival in PC patients [35]. The data presented here suggest that the phenotype and functional traits of human monocytes depend on the immune environment to which these cells are exposed. Therefore, targeting monocytes in the circulation is an attractive and novel 
approach, which could decrease Mo-MDSC in the tumor microenvironment.

ALDH1 enzyme activity defines a subpopulation of tumor cells which exhibit stem cell-like properties and whose prevalence correlates with survival in PC Additionally, a number of cell surface markers are co-expressed with ALDH1, such as CD44, CD24, CD133, and CXCR4 $[36,37]$. Evidence in mice suggests that ALDH1 has an important role in the embryological development of the pancreas [38, 39]. However, a subpopulation of ALDH$1^{\text {Bright }}$ CSCs exhibit enhanced chemoresistance and metastasis [15]. Despite much progress, further work is needed to find better phenotypic and functional markers of CSCs in human malignancy.

STAT3 is a crucial transcription factor involved in inflammation. In murine models, pSTAT3 has been shown to regulate the expansion of myeloid progenitors as well as MDSC [40, 41].

Mo-MDSC depend on STAT3 for their immunosuppressive properties, such as the production of arginase-1 [30]. We show here that STAT3 activation in Mo-MDSC is also critical for enhancing the CSC population in PC. It is likely that STAT3 phosphorylation reprograms monocytes to acquire a pro-tumor, immunosuppressive (MDSC) phenotype. We show that STAT3 inhibition completely abrogates the ability of Mo-MDSC to enhance the ALDH $1^{\text {Bright }}$ CSC population in vitro.

Bone marrow-derived myeloid cells make up a significant proportion of the stroma in solid tumors where they promote proliferation and survival of tumor cells. Recent reports demonstrate that tumor-infiltrating macrophages support early tumorigenesis by inducing EMT through TGF- $\beta$ signaling [42]. In addition, other studies have shown that there is cross talk between MDSC and macrophages that polarizes macrophages into an M2 phenotype [43] which contribute to EMT [44]. Like macrophages, the high frequency of Mo-MDSC-infiltrating tumors suggests these cells are critical in mediating immune suppression in cancer patients. Our murine model and in vitro studies confirm that in addition to the direct suppression of $\mathrm{T}$ cells, Mo-MDSC also play an important role in promoting tumor stemness and EMT in a STAT3-dependent manner and this effect is independent of any other cell type in the tumor. Our data further show that Mo-MDSC and macrophages can be distinguished based on expression of HLA-DR (Figs. 4, 5). Thus, we conclude that both Mo-MDSC and macrophages promote EMT, but further studies are required to assess possible mechanistic, spatial, and/or temporal differences.

Overall, our study shows that Mo-MDSC in both mice and humans promote ALDH1 ${ }^{\text {Bright }} \mathrm{CSCs}$ in PC through STAT3 activation. Therefore, an improved understanding of the interactions between MDSC and CSCs is crucial for the development of novel therapies that may intercept this communication. Our findings suggest that there are multiple pathophysiologic pathways, which could be therapeutically targeted in PC. Blocking tumor-induced myelopoiesis [45], the recruitment of monocytes to the tumor microenvironment, e.g., through blockade of chemokine receptors, the conversion of monocytes into Mo-MDSC, and the STAT3-dependent enhancement of tumor stemness all offer opportunities to thwart the tumor-promoting effects on myeloid cells in this disease. In conclusion, we show that monocytes can become Mo-MDSC in the presence of tumor by acquiring immunosuppressive properties. Furthermore, Mo-MDSC infiltrate tumors where they promote cancer stemness in a STAT3-dependent manner.

Acknowledgments David C. Linehan acknowledges funding from NIH 5R01CA168863. David C. Linehan and S. Peter Goedegebuure acknowledge funding from the WU/Pfizer Biomedical Research Grant PW0457. David G. DeNardo acknowledges support from the Lustgarten Foundation, V Foundation, Edward Mallinckrodt Jr. Award, the Cancer Research Foundation, and Siteman Cancer Center Career Development Award. David C. Linehan, Andrea Wang-Gillam, S. Peter Goedegebuure, and David G. DeNardo acknowledge the Siteman Cancer Center-Cancer Frontier Fund Team Science Award. Jonathan B. Mitchem and Dominic E. Sanford acknowledge funding from NCI Grant T32 CA 009621.

Conflict of interest David C. Linehan has a commercial research grant from Pfizer. The other authors disclosed no potential conflicts of interest.

Open Access This article is distributed under the terms of the Creative Commons Attribution License which permits any use, distribution, and reproduction in any medium, provided the original author(s) and the source are credited.

\section{References}

1. Siegel R, Ma J, Zou Z, Jemal A (2014) Cancer statistics, 2014. CA Cancer J Clin 64:9-29

2. Clark CE, Beatty GL, Vonderheide RH (2009) Immunosurveillance of pancreatic adenocarcinoma: insights from genetically engineered mouse models of cancer. Cancer Lett 279:1-7

3. Bronte V, Chappell DB, Apolloni E, Cabrelle A, Wang M, Hwu P, Restifo NP (1999) Unopposed production of granulocytemacrophage colony-stimulating factor by tumors inhibits CD8+ $\mathrm{T}$ cell responses by dysregulating antigen-presenting cell maturation. J Immunol 162:5728-5737

4. Melani C, Chiodoni C, Forni G, Colombo MP (2003) Myeloid cell expansion elicited by the progression of spontaneous mammary carcinomas in c-erbB-2 transgenic BALB/c mice suppresses immune reactivity. Blood 102:2138-2145

5. Qian BZ, Li J, Zhang H, Kitamura T, Zhang J, Campion LR, Kaiser EA, Snyder LA, Pollard JW (2011) CCL2 recruits inflammatory monocytes to facilitate breast-tumour metastasis. Nature 475:222-225

6. Grivennikov SI, Greten FR, Karin M (2010) Immunity, inflammation, and cancer. Cell 140:883-899 
7. Porembka MR, Mitchem JB, Belt BA, Hsieh CS, Lee HM, Herndon J, Gillanders WE, Linehan DC, Goedegebuure P (2012) Pancreatic adenocarcinoma induces bone marrow mobilization of myeloid-derived suppressor cells which promote primary tumor growth. Cancer Immunol Immunother 61:1373-1385

8. Gabitass RF, Annels NE, Stocken DD, Pandha HA, Middleton GW (2011) Elevated myeloid-derived suppressor cells in pancreatic, esophageal and gastric cancer are an independent prognostic factor and are associated with significant elevation of the Th2 cytokine interleukin-13. Cancer Immunol Immunother 60:1419-1430

9. Ostrand-Rosenberg S, Sinha P, Beury DW, Clements VK (2012) Cross-talk between myeloid-derived suppressor cells (MDSC), macrophages, and dendritic cells enhances tumor-induced immune suppression. Semin Cancer Biol 22:275-281

10. Korc M (2007) Pancreatic cancer-associated stroma production. Am J Surg 194:S84-S86

11. Clarke MF, Dick JE, Dirks PB, Eaves CJ, Jamieson CH, Jones DL, Visvader J, Weissman IL, Wahl GM (2006) Cancer stem cells - perspectives on current status and future directions: AACR workshop on cancer stem cells. Cancer Res 66:9339-9344

12. Li C, Heidt DG, Dalerba P, Burant CF, Zhang L, Adsay V, Wicha M, Clarke MF, Simeone DM (2007) Identification of pancreatic cancer stem cells. Cancer Res 67:1030-1037

13. Kim MP, Fleming JB, Wang H, Abbruzzese JL, Choi W, Kopetz S, McConkey DJ, Evans DB, Gallick GE (2011) ALDH activity selectively defines an enhanced tumor-initiating cell population relative to CD133 expression in human pancreatic adenocarcinoma. PLoS One 6:e20636

14. Deng S, Yang X, Lassus H et al (2010) Distinct expression levels and patterns of stem cell marker, aldehyde dehydrogenase isoform 1 (ALDH1), in human epithelial cancers. PLoS One 5:e10277

15. Mitchem JB, Brennan DJ, Knolhoff BL et al (2013) Targeting tumor-infiltrating macrophages decreases tumor-initiating cells, relieves immunosuppression, and improves chemotherapeutic responses. Cancer Res 73:1128-1141

16. Rasheed ZA, Yang J, Wang Q et al (2010) Prognostic significance of tumorigenic cells with mesenchymal features in pancreatic adenocarcinoma. J Natl Cancer Inst 102:340-351

17. Jinushi M, Chiba S, Yoshiyama H, Masutomi K, Kinoshita I, Dosaka-Akita H, Yagita H, Takaoka A, Tahara H (2011) Tumorassociated macrophages regulate tumorigenicity and anticancer drug responses of cancer stem/initiating cells. Proc Natl Acad Sci USA 108:12425-12430

18. Mimeault M, Batra SK (2013) Hypoxia-inducing factors as master regulators of stemness properties and altered metabolism of cancer- and metastasis-initiating cells. J Cell Mol Med 17:30-54

19. Gabrilovich DI, Ostrand-Rosenberg S, Bronte V (2012) Coordinated regulation of myeloid cells by tumours. Nat Rev Immunol 12:253-268

20. Talmadge JE, Gabrilovich DI (2013) History of myeloid-derived suppressor cells. Nat Rev Cancer 13:739-752

21. Schust J, Sperl B, Hollis A, Mayer TU, Berg T (2006) Stattic: a small-molecule inhibitor of STAT3 activation and dimerization. Chem Biol 13:1235-1242

22. Besmer DM, Curry JM, Roy LD et al (2011) Pancreatic ductal adenocarcinoma mice lacking mucin 1 have a profound defect in tumor growth and metastasis. Cancer Res 71:4432-4442

23. Corbett TH, Roberts BJ, Leopold WR, Peckham JC, Wilkoff LJ, Griswold DP Jr, Schabel FM Jr (1984) Induction and chemotherapeutic response of two transplantable ductal adenocarcinomas of the pancreas in C57BL/6 mice. Cancer Res 44:717-726

24. Whatcott C, Han H, Posner RG, Von Hoff DD (2013) Tumorstromal interactions in pancreatic cancer. Crit Rev Oncog $18: 135-151$
25. Liu F, Poursine-Laurent J, Link DC (2000) Expression of the G-CSF receptor on hematopoietic progenitor cells is not required for their mobilization by G-CSF. Blood 95:3025-3031

26. McLemore ML, Grewal S, Liu F, Archambault A, Poursine-Laurent J, Haug J, Link DC (2001) STAT-3 activation is required for normal G-CSF-dependent proliferation and granulocytic differentiation. Immunity 14:193-204

27. Liu F, Wu HY, Wesselschmidt R, Kornaga T, Link DC (1996) Impaired production and increased apoptosis of neutrophils in granulocyte colony-stimulating factor receptor-deficient mice. Immunity 5:491-501

28. Gabrilovich DI, Bronte V, Chen SH, Colombo MP, Ochoa A, Ostrand-Rosenberg S, Schreiber H (2007) The terminology issue for myeloid-derived suppressor cells. Cancer Res 67:425; author reply 6

29. Gabrilovich DI, Nagaraj S (2009) Myeloid-derived suppressor cells as regulators of the immune system. Nat Rev Immunol 9:162-174

30. Vasquez-Dunddel D, Pan F, Zeng Q et al (2013) STAT3 regulates arginase-I in myeloid-derived suppressor cells from cancer patients. J Clin Invest 123:1580-1589

31. Hoechst B, Ormandy LA, Ballmaier M, Lehner F, Kruger C, Manns MP, Greten TF, Korangy F (2008) A new population of myeloid-derived suppressor cells in hepatocellular carcinoma patients induces CD4(+)CD25(+)Foxp3(+) T cells. Gastroenterology 135:234-243

32. Poschke I, Mougiakakos D, Hansson J, Masucci GV, Kiessling R (2010) Immature immunosuppressive CD14+ HLA-DR-/low cells in melanoma patients are Stat3hi and overexpress CD80, CD83, and DC-sign. Cancer Res 70:4335-4345

33. Marigo I, Bosio E, Solito S et al (2010) Tumor-induced tolerance and immune suppression depend on the C/EBPbeta transcription factor. Immunity 32:790-802

34. Wang L, Yi T, Kortylewski M, Pardoll DM, Zeng D, Yu H (2009) IL-17 can promote tumor growth through an IL-6-Stat3 signaling pathway. J Exp Med 206:1457-1464

35. Sanford DE, Belt BA, Panni RZ et al (2013) Inflammatory monocyte mobilization decreases patient survival in pancreatic cancer: a role for targeting the CCL2/CCR2 axis. Clin Cancer Res 19:3404-3415

36. Rasheed ZA, Matsui W (2012) Biological and clinical relevance of stem cells in pancreatic adenocarcinoma. J Gastroenterol Hepatol 27(Suppl 2):15-18

37. Hermann PC, Huber SL, Herrler T, Aicher A, Ellwart JW, Guba M, Bruns CJ, Heeschen C (2007) Distinct populations of cancer stem cells determine tumor growth and metastatic activity in human pancreatic cancer. Cell Stem Cell 1:313-323

38. Duester G (2008) Retinoic acid synthesis and signaling during early organogenesis. Cell 134:921-931

39. Rovira M, Scott SG, Liss AS, Jensen J, Thayer SP, Leach SD (2010) Isolation and characterization of centroacinar/terminal ductal progenitor cells in adult mouse pancreas. Proc Natl Acad Sci USA 107:75-80

40. Lesina M, Kurkowski MU, Ludes K et al (2011) Stat3/Socs3 activation by IL- 6 transsignaling promotes progression of pancreatic intraepithelial neoplasia and development of pancreatic cancer. Cancer Cell 19:456-469

41. Zhang H, Nguyen-Jackson H, Panopoulos AD, Li HS, Murray PJ, Watowich SS (2010) STAT3 controls myeloid progenitor growth during emergency granulopoiesis. Blood 116:2462-2471

42. Bonde AK, Tischler V, Kumar S, Soltermann A, Schwendener RA (2012) Intratumoral macrophages contribute to epithelialmesenchymal transition in solid tumors. BMC Cancer 12:35

43. Sinha P, Clements VK, Bunt SK, Albelda SM, Ostrand-Rosenberg S (2007) Cross-talk between myeloid-derived suppressor 
cells and macrophages subverts tumor immunity toward a type 2 response. J Immunol 179:977-983

44. Liu CY, Xu JY, Shi XY, Huang W, Ruan TY, Xie P, Ding JL (2013) M2-polarized tumor-associated macrophages promoted epithelial-mesenchymal transition in pancreatic cancer cells, partially through TLR4/IL-10 signaling pathway. Lab Invest 93:844-854
45. Bayne LJ, Beatty GL, Jhala N, Clark CE, Rhim AD, Stanger BZ, Vonderheide RH (2012) Tumor-derived granulocyte-macrophage colony-stimulating factor regulates myeloid inflammation and $\mathrm{T}$ cell immunity in pancreatic cancer. Cancer Cell 21:822-835 